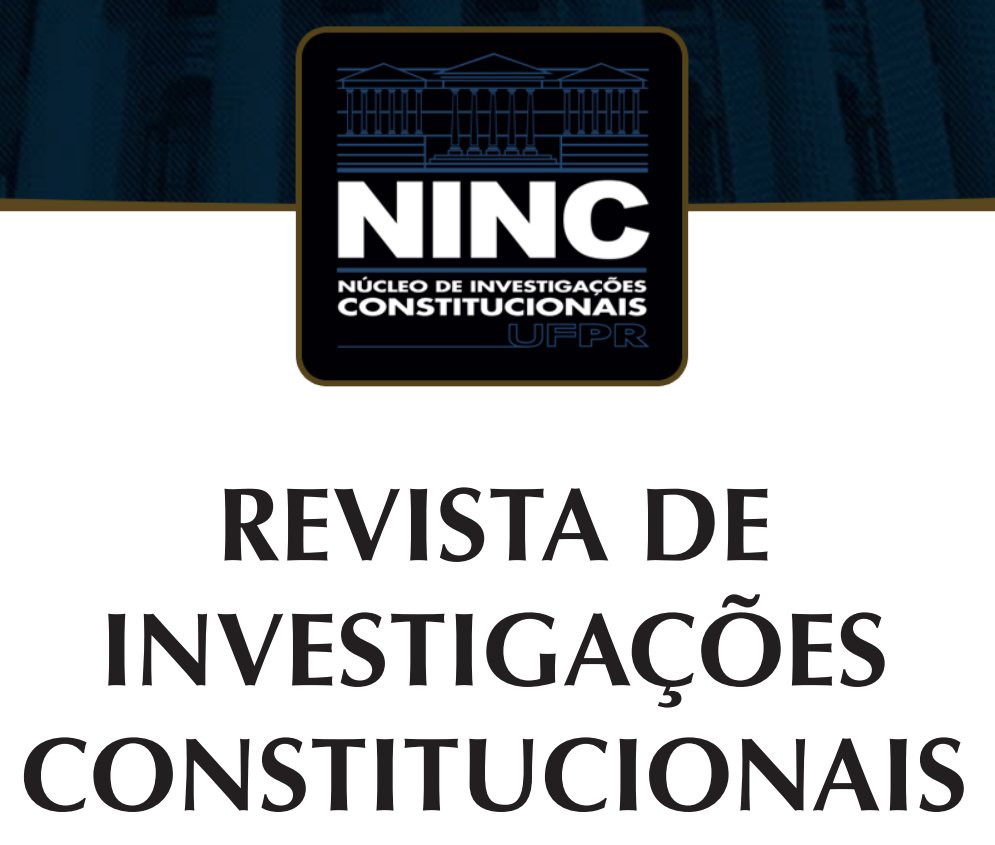

JOURNAL OF CONSTITUTIONAL RESEARCH

vol. 7 | n. 2 | maio/agosto 2020 | ISSN 2359-5639 | Periodicidade quadrimestral Curitiba | Núcleo de Investigações Constitucionais da UFPR | www.ninc.com.br 


\title{
Autorização para uso de medicamentos com princípios ativos proscritos no Brasil
}

\section{Authorization for use of medicines with forbidden principles in Brazil}

\author{
EMERSON GABARDO 1 , II, * \\ 'Pontifícia Universidade Católica do Paraná (Curitiba, Paraná, Brasil) \\ " Universidade Federal do Paraná (Curitiba, Paraná, Brasil) \\ emerson.gabardo@pucpr.br \\ http://orcid.org/0000-0002-1798-526X \\ RODRIGO MACIEL CABRAL I, ** \\ ' Pontifícia Universidade Católica do Paraná (Curitiba, Paraná, Brasil) \\ rmacielcabral@gmail.com \\ http://orcid.org/0000-0003-1837-6121 \\ Recebido/Received: 09.09.2020 / September $9^{\text {th }}, 2020$ \\ Aprovado/Approved: $29.10 .2020 /$ October $29^{\text {th }}, 2020$
}

Resumo

O trabalho visa à análise da possibilidade de se obter autorização para uso de medicamentos que possuem como princípio ativo substâncias proscritas no Brasil. Por meio de pesquisa em material bibliográfico interdisciplinar, legislação e julgados, esta análise abarca desde a evolução histórica do uso medicinal de substâncias proibidas até mesmo proposta concreta para que se possa utilizar tais medicamentos apesar da atual proibição com

\section{Abstract}

The study aims to analyze the possibility of obtaining authorization for use of drugs that have as active principle banned substances in Brazil. Through a methodology of research in interdisciplinary bibliographic material, legislation and judgments, this study covers from the historical evolution of medicinal use of forbidden substances to even a concrete proposal for use of those drugs, despite of the actual prohibition with criminal reprimand. We begin to revisit

Como citar esse artigo/How to cite this article: GABARDO, Emerson; CABRAL, Rodrigo Maciel. Autorização para uso de medicamentos com princípios ativos proscritos no Brasil. Revista de Investigações Constitucionais, Curitiba, vol. 7, n. 2, p. 473-515, maio/ago. 2020. DOl: 10.5380/rinc.v7i2.76339.

* Professor Titular de Direito Administrativo da Pontifícia Universidade Católica do Paraná (Curitiba-PR, Brasil). Professor Adjunto de Direito Administrativo da UFPR (Curitiba-PR, Brasil). Doutor em Direito do Estado pela UFPR com Pós-doutorado em Direito Público Comparado pela Fordham University School of Law - EUA (2012-2013). Em 2020 foi Professor Visitante Sênior na Universidade da Califórnia - UCI (EUA).E-mail: e.gab@uol.com.br.

** Pós-graduando em Licitações e Contratos Administrativos pela Pontifícia Universidade Católica do Paraná - PUCPR (Curitiba-PR, Brasil). Pesquisador membro do Núcleo de Pesquisa em Políticas Públicas e Desenvolvimento Humano - NUPED/ PUCPR. Especialista em Direito Administrativo pelo Instituto de Direito Romeu Felipe Bacellar. E-mail: rmacielcabral@gmail.com. 
reprimenda criminal. Começa-se a revisitar tais proibições de substratos e reconhecer a possibilidade de utilização de novos medicamentos, como ocorreu com o canabidiol: a substância anteriormente de uso proibido, hoje já foi retirada deste rol, com a criação de procedimento administrativo para sua importação por intermédio de análise da Agência Nacional de Vigilância Sanitária (ANVISA). Assim, analisa-se a concessão destes medicamentos pela via administrativa, pelo enfoque legislativo e também judicial. No caso em questão, analisa-se igualmente a proposta de critérios formulada no julgamento da Repercussão Geral n 500, para medicamentos sem registro da ANVISA. A concessão de autorização deve observar à comprovação da necessidade do tratamento e a constatação da eficácia do medicamento, objetivando a consolidação do direito fundamental à saúde e à vida sob uma perspectiva não tradicional, para pacientes que precisam dos medicamentos com princípios ativos proibidos no Brasil.

Palavras-chave: medicamentos; direito à saúde; ANVISA; substâncias proibidas; canabidiol. such prohibitions of substrates and recognize the possibility of using new drugs, as occurred with cannabidiol: this substance previously prohibited, has already been removed from that list, and it was also created an administrative procedure for its importation trough analysis by the National Sanitary Surveillance Agency (ANVISA). Thus, it's necessary to analyze the concession of these drugs by administrative way, legislative and also judicial approach. It's also necessary to analyze the criteria proposal made for judgement of the General Repercussion Thesis $n$. 500, for medicines without ANVISA's registration. The granting of authorization must comply proof of need for treatment and the confirmation of drug effectiveness, aiming to consolidate the fundamental right to health and life from a non-traditional perspective, for patients who need these drugs with forbidden active principles in Brazil.

Keywords: medicines; right to health; ANVISA; forbidden substances; cannabidiol.

\section{SUMÁRIO}

1. Introdução; 2. A possibilidade e a necessidade de uso de substâncias proscritas: tratamentos alternativos na garantia do Direito à saúde e à vida; 3. Critérios para concessão de medicamentos sem registro na ANVISA; 4. A utilização de fármacos com substâncias proibidas: regulamentação e judicialização; 5. Conclusões; 6 . Referências.

\section{INTRODUÇÃO}

A concessão de medicamentos pela via judicial é um fenômeno crescente no Brasil desde que consolidado o modelo de Estado social instituído pela Constituição de 1988. Por consequência, os desdobramentos do tema têm repercutido na doutrina e na jurisprudência. Conforme os últimos levantamentos realizados pela Organização Mundial da Saúde, em 2014 o Brasil teve um gasto total com saúde que representa apenas 8,3\% do Produto Interno Bruto. ${ }^{1}$ Estes dados representam 6,8\% do orçamento público do governo federal, um índice muito abaixo da média mundial, que é de $11,7 \%$ do orçamento. ${ }^{2}$ Em que pese, inicialmente, parecer uma grande quantidade de recursos, é certo que o colapso organizacional do sistema de saúde brasileiro gera cada vez mais imposições judiciais para o fornecimento de fármacos. Afinal, a quantia orçamentária

OMS. Dados estatísticos sobre o Brasil. Disponível em: http://www.who.int/countries/bra/es/. Acesso em: 28.09.2018.

2 CHADE, Jamil. Orçamento para saúde no Brasil fica abaixo da média mundial, diz OMS. Disponível em: https://saude.estadao.com.br/noticias/geral,orcamento-para-saude-no-brasil-fica-abaixo-da-media-mundial,70001788024. Acesso em: 28.09.2018. 
prevista não atende a totalidade da demanda da população, principalmente quando se está perante medicamentos de alto custo. ${ }^{3}$

Os direitos humanos positivados na forma de direitos fundamentais foram construções históricas, fundados por embates entre movimentos da sociedade civil que pleiteavam melhores condições e, de outro lado, o poder dominante do Estado. ${ }^{4}$ Ao consagrar extenso rol de direitos fundamentais, a Constituição de 1988 fixou uma gama de princípios e direitos prestacionais, os quais firmam um Estado social de Direito em sentido material. ${ }^{5}$ Assim, a judicialização dos direitos sociais não passa a ser mera expectativa ou elemento estranho à justiça brasileira, tratando-se de fenômeno crescente, como forma de concretizar as demandas sociais. Gize-se que os serviços públicos estão vinculados ao preenchimento de direitos fundamentais e, ${ }^{6}$ especificamente no tocante ao direito à saúde, ao tratar-se de direito social que exige uma prestação positiva por parte do Estado, ainda que não existente lei regulamentadora, poderá ser postulado judicialmente, mesmo que desborde do mínimo existencial, e sem que seja necessária impetração de mandado de injunção. Por um lado, a Constituição de 1988 criou um sistema único de saúde, interfederativo e que abrange todo o território nacional; por outro, ainda experimenta-se graves problemas de gestão deste sistema. ${ }^{8}$

Os dados do relatório "Justiça em números 2017" demonstraram que somente no ano de 2016 os pedidos de fornecimento de medicamentos pelo SUS alcançaram o montante de 312.147 processos, um aumento de $56 \%$ em relação ao ano anterior, que contabilizou 200.090 pedidos de fármacos. ${ }^{9}$ Tamanho é o impacto da concessão pela via judicial que, exclusivamente em 2015, os vinte medicamentos mais demandados

\footnotetext{
3 FREITAS, Daniel Castanha de. Direito fundamental à saúde e medicamentos de alto custo. Belo Horizonte: Fórum, 2018.

4 GIMENEZ, Charlise de Paula Colet; DEL'OLMO, Florisbal de Souza; ANGELIN, Rosângela. Dos Direitos Humanos e dos Conflitos na Sociedade Líquida pós-moderna. Nomos - Revista do Programa de pós-graduação da UFC, Fortaleza, v. 37.2, jul./dez. 2017, p. 271.

5 SCHIER, Paulo Ricardo. Constitucionalização no contexto da Constituição de 1988. In: CLÈVE, Clèmerson Merlin (Org.). Direito Constitucional brasileiro. v. 1. São Paulo: Revista dos Tribunais, 2014, p. 45.

$6 \quad$ PAIVA, Leonardo Lindroth de; LEINDORF, Cecilia de Aguilar. O usuário do serviço Público como consumidor: visões do direito administrativo e do consumidor e sua atual aplicação. In: BETTES, Janaína Maria; DE PAIVA, Leonardo Lindroth; Lucimara Deretti (Coord.). Temas de Desenvolvimento e Socioambientalismo. Curitiba: CRV,2016. P. 167

7 HACHEM, Daniel Wunder. Tutela administrativa efetiva dos direitos fundamentais sociais: por uma implementação espontânea, integral e igualitária. Tese (Doutorado) - Universidade Federal do Paraná, Setor de Ciências Jurídicas, Programa de Pós-Graduação. Curitiba, 2014. p. 153.

8 STRAPAZZON, Carlos Luiz. Direitos constitucionais de seguridade social no Brasil: uma abordagem orientada por direitos humanos. A\&C - Revista de Direito Administrativo \& Constitucional, Belo Horizonte, ano 17, n. 67, jan./ mar. 2017. P. 211

9 OBSERVATÓRIO DE ANÁLISE POLÍTICA EM SAÚDE. Relatório de acompanhamento de políticas. Disponível em http://www.analisepoliticaemsaude.org/oaps/matriz/analises/2/. Acesso em: 04.09.2018
} 
fizeram com que a União despendesse $\mathrm{R} \$ 959.785 .237,40$ para cobrir o fornecimento. ${ }^{10}$ Note-se que este dado somente revela os custos da União com as condenações judiciais. Ainda há de se considerar que Estados e Municípios também podem ser condenados judicialmente ao fornecimento de medicamentos.

Sob outro viés, revela-se ainda mais patente a desorganização de finanças dos entes federativos, tendo em vista que a priorização de determinados gastos - que não englobam direitos fundamentais, ou sequer o mínimo existencial - distanciam a Administração Pública do cumprimento espontâneo das demandas relativas ao direito fundamental à saúde. A título ilustrativo, cabe a consideração de que parte das condenações supramencionadas da União poderia muito bem ser coberta com um corte de gastos em outros setores não relevantes, tais como: o valor pago por aquele ente federativo em auxílio-moradia, que alcançou o montante de R\$ 817 milhões em 2017; ${ }^{11}$ ou ainda os valores utilizados para pagamento dos gastos em cartões corporativos, os quais implicaram, por exemplo, gastos de $\mathrm{R} \$ 2.414 .816,71$ em um único cartão vinculado à Presidência da República, no período de janeiro a março de 2019. ${ }^{12}$ Apesar de existir um conjunto significativo de comandos constitucionais para que seja realizado um adequado planejamento das escolhas públicas, o Brasil ainda carece de uma atuação sistemática e eficiente na matéria. ${ }^{13}$ Pior que isso, muitas vezes as escolhas públicas são tomadas com base em preocupações muito afastadas do modelo de Estado social, sendo determinadas por um sistema econômico voltado aos interesses das elites dominantes, das corporações, e dos detentores do capital supranacional. Para estes grupos, sempre serão as despesas com educação, saúde e previdência as vilãs do orçamento. ${ }^{14}$ Apesar do Brasil estar entre as dez maiores economias do mundo e possuir um produto interno bruto muito significativo, não consegue sair da lista global dos países mais desiguais. Olvida-se da proteção dos direitos fundamentais, aos quais a Constituição exige

\footnotetext{
10 AGU. Judicialização da saúde no Brasil: Principais Projetos Desenvolvidos pela Coordenação de Assuntos Judiciais. Disponível em: http://portalarquivos2.saude.gov.br/images/pdf/2017/maio/17/ JUDICIALIZACAO\%20DA\%20SAUDE\%20NO\%20BRASIL\%20Principais\%20Projetos\%20Desenvolvidos\%20pela\%20Coordenacao\%20de\%20Assuntos\%20Judiciais.pdf. Acesso em: 10.09.2018.

11 TRUFFI, Renan; CARDOSO, Daiene. Auxílio-moradia custa R\$ 817 mi à União. Disponível em: https:// politica.estadao.com.br/noticias/geral,auxilio-moradia-custa-r-817-mi-a-uniao,70002176117. Acesso em: 28.09.2018.

12 PORTAL DA TRANSPARÊNCIA. Detalhamento dos gastos por meio de cartão de pagamento. Disponível em: http://www.portaltransparencia.gov.br/cartoes/consulta?ordenarPor=valorTotal\&direcao=desc. Acesso em: 20.05.2019.

13 VALLE, Vanice Lírio do. Planejamento orçamentário e políticas públicas: explorando uma alternativa de reconciliação pela indução. Revista de Investigações Constitucionais, Curitiba, v. 5, n. 2, p. 113-134, mai./ago. 2018.

14 Prova disso é a absurda Emenda Constitucional 95/2016. Sobre o assunto, ver: MARIANO, Cynara Monteiro. Emenda constitucional 95/2016 e o teto dos gastos públicos: Brasil de volta ao estado de exceção econômico e ao capitalismo do desastre. Revista de Investigações Constitucionais, Curitiba, v. 4, n. 1, p. 259-281, jan./abr. 2017.
} 
respeito por parte dos agentes públicos em geral, devendo ser igualmente respeitados no âmbito das relações privadas, entre particulares. ${ }^{15}$

De todo modo, voltando ao problema estrutural, na globalidade destas demandas, o Judiciário aprecia desde casos de medicamentos já fornecidos pelo SUS, ${ }^{16}$ até medicamentos de alto custo para portadores de doenças graves que não possuem condições financeiras, conforme reconhecida tese de repercussão geral do Supremo Tribunal Federal. ${ }^{17}$ Não distante desta situação, encontra-se na jurisprudência casos de concessão de medicamentos que não possuem registros na Agência Nacional de Vigilância Sanitária, pelo que o Supremo Tribunal Federal fixou parâmetros para determinar que seja possível, pela via judicial, haver determinação para que a Administração Pública os forneça. Estes patamares que estão contidos no voto do Ministro Luis Roberto Barroso, no Recurso Extraordinário n 657.718/MG (Repercussão Geral n 500), envolvem critérios de existência de solicitação de registro na ANVISA, assim como análise da eficácia do tratamento pleiteado, dentre outros.

Ainda dentro deste universo de medicamentos que não possuem registro, há alguns demandados que inclusive possuem princípio ativo proibido no país, como é o caso de medicamentos à base de opioides e até mesmo substratos provenientes de cogumelos alucinógenos. O rol de substâncias e medicamentos que estão sujeitos a um regime de controle especial no Brasil é regulamentado pela Portaria n 344/1998 do Ministério da Saúde, na qual também constam as substâncias de uso proscrito (Lista F).

O manejo (lato sensu) destas substâncias contidas na lista F ensejam a aplicação das penas previstas no art. 33 da Lei n 11.343/2006, com pena de reclusão de até 15 anos. ${ }^{18}$ Entretanto, tais proibições vêm sendo revistas diante da possibilidade do uso

15 SALGADO, Eneida Desiree. Populismo judicial, moralismo e o desprezo à Constituição: a democracia entre velhos e novos inimigos. Revista Brasileira de Estudos Políticos, Belo Horizonte, n. 117, jul./dez. 2018, p. 201; DEZAN, Sandro Lucio; BRASIL JÚNIOR, Samuel Meira. A juridicidade do Estado-administração na concretização de políticas públicas de saúde - Um método para a justificação da eficácia horizontal dos direitos fundamentais. A\&C - Revista de Direito Administrativo \& Constitucional, Belo Horizonte, ano 16, n. 63, p. 211-238, jan./mar. 2016.

16 TRF4, AC/RN 2009.70.03.001191-1, 3a Turma, Relator Carlos Eduardo Thompson Flores Lenz. D. E. 07/01/2010;

17 STF. Tema de Repercussão Geral no 6 - RE 566471. Relator Min. Marco Aurélio. Disponível em: http://www. stf.jus.br/portal/jurisprudenciaRepercussao/verAndamentoProcesso.asp?incidente $=2565078 \&$ numeroProcesso $=566471 \&$ classeProcesso $=$ RE\&numeroTema $=6$. Acesso em: 20.05.2019.

18 Art. 33. Importar, exportar, remeter, preparar, produzir, fabricar, adquirir, vender, expor à venda, oferecer, ter em depósito, transportar, trazer consigo, guardar, prescrever, ministrar, entregar a consumo ou fornecer drogas, ainda que gratuitamente, sem autorização ou em desacordo com determinação legal ou regulamentar: Pena - reclusão de 5 (cinco) a 15 (quinze) anos e pagamento de 500 (quinhentos) a 1.500 (mil e quinhentos) dias-multa. § 1-Nas mesmas penas incorre quem: I - importa, exporta, remete, produz, fabrica, adquire, vende, expõe à venda, oferece, fornece, tem em depósito, transporta, traz consigo ou guarda, ainda que gratuitamente, sem autorização ou em desacordo com determinação legal ou regulamentar, matéria-prima, insumo ou produto químico destinado à preparação de drogas; II - semeia, cultiva ou faz a colheita, sem autorização ou em desacordo com determinação legal ou regulamentar, de plantas que se constituam em matéria-prima para a preparação de drogas; III - utiliza local ou bem de qualquer natureza de que tem a propriedade, posse, 
controlado para fins medicinais, como é o exemplo do canabidiol que foi retirado do rol de substâncias proscritas e apresenta utilidade em diversos distúrbios neuropsiquiátricos..$^{19}$ Atualmente, levanta-se a discussão acerca da liberação total de outro princípio ativo da maconha, o tetraidrocanabinol (THC), eis que demonstrada a possibilidade de utilização para vários tratamentos, desde aliviar os sintomas da quimioterapia até mesmo glaucoma, convulsões e espasmos em pacientes portadores de esclerose múltipla. De forma ainda mais recente, a ANVISA aprovou a Resolução de Diretoria Colegiada no 325, de 3 de dezembro de 2019, a qual atualizou a lista de substâncias proibidas da Lista F da Portaria no 344/1998, permitindo a venda de medicamentos à base de Cannabis Sativa em território nacional.

Neste sentido, o presente estudo volta-se para a análise da possibilidade de concessão de autorização para uso de medicamentos que possuem princípios ativos ilícitos constantes na Lista F da Portaria n 344/1998 do Ministério da Saúde, em favor da dignidade da pessoa humana e proteção do direito à saúde e à vida.

\section{A POSSIBILIDADE E A NECESSIDADE DE USO DE SUBSTÂNCIAS PROSCRITAS: TRATAMENTOS ALTERNATIVOS NA GARANTIA DO DIREITO À SAÚDE E À VIDA}

Primeiramente, ressalte-se que o objetivo da pesquisa em questão não visa a discutir a liberação ou exclusão de qualquer princípio ativo do rol de substâncias proscritas na Portaria no 344/98, mas sim analisar a possibilidade jurídica de utilização destas fórmulas em tratamentos médicos controlados, mesmo com a proibição decorrente daquela Portaria e da Lei $n^{\circ} 11.343 / 2006$. No entorno desta questão criaram-se tabus, mitos e preconceitos, haja vista que em regra os medicamentos controlados constituem ou possuem relação com alguma substância entorpecente.

Após o fim da segunda Guerra Mundial, iniciou-se na Europa e nos Estados Unidos a edição de leis restringindo o uso de estupefacientes, pelo que o século XX acabou por proibir e estigmatizar drogas e drogados, considerando-os perigosos elementos que desagregam a sociedade. ${ }^{20}$ Ao revés, a evolução histórica do desenvolvimento da produção de diversas substâncias consideradas "drogas" (proibidas no Brasil) muito tem a acrescentar para o tratamento ou amenização dos sintomas de doenças raras, em

\footnotetext{
administração, guarda ou vigilância, ou consente que outrem dele se utilize, ainda que gratuitamente, sem autorização ou em desacordo com determinação legal ou regulamentar, para o tráfico ilícito de drogas

19 BARROS, Daniel Martins de. A liberação do Canabidiol. Disponível em: https://emais.estadao.com.br/blogs/daniel-martins-de-barros/a-liberacao-do-canabidiol/. Acesso em: 10.09.2018.

20 VIEIRA, João. O homem e as drogas: o penoso caminho do retrocesso. São Paulo: Letras\& Letras, 1996. p. 58.
} 
especial que atingem o sistema neurológico. ${ }^{21}$ Inclusive, há muito tempo já se desenvolve no campo das ciências biológicas pesquisas sobre o tema.

Sigmund Freud dedicou muitos de seus estudos aos efeitos fisiopatológicos do uso da cocaína, realizando diversos testes, essencialmente sobre o efeito anestésico que a droga possuía, levando em consideração a utilização dessa substância (de longa data) pelos povos que habitavam a região andina da América do Sul. ${ }^{22}$ Freud chegou a mencionar em seus escritos que a propriedade da cocaína no entorpecimento da pele e das mucosas com que entra em contato pode levar a outros usos desta substância principalmente para doenças das mucosas: "graças a essa propriedade anestésica, o uso da cocaína difundir-se-á em um próximo amanhã e outros usos que se originam do efeito anestésico da cocaína podem muito bem se desenvolver".23 Karl Köller, oftalmologista contemporâneo de Freud passou a acompanhar o trabalho desenvolvido pelo psiquiatra sobre o uso de cocaína como anestésico realizando pesquisas paralelas e, mais tarde, comunicou a descoberta da anestesia tópica do olho humano com o uso de uma solução à base de cocaína, no Congresso Oftalmológico de Heidelberg. ${ }^{24} \mathrm{O}$ estudo em questão foi o grande responsável pela descoberta da anestesia local, o que rendeu diversas homenagens e congratulações a Köller. ${ }^{25}$

Ressalte-se, neste sentido, as múltiplas funções que se pode extrair de uma mesma substância, inclusive possibilitando inúmeras descobertas no plano da ciência e do desenvolvimento para melhor atender o direito à saúde, não podendo se tratar do tema com resistência ou intolerância - ainda que seja realmente um tema sensível. De fato, vários princípios ativos possuem dois lados, podendo causar tanto um prejuízo à saúde quanto a sua promoção.

Atualmente, os opiáceos utilizados como fármacos contra a dor são de venda controlada no mercado, podendo-se citar como exemplo a codeína, a morfina, a hidrocodona, a oximorfona e o fentanil. ${ }^{26}$ O Ópio consta na Lista A1, n 72, da Portaria 344/1998, sendo constatado como substância entorpecente, podendo ser vendido

\footnotetext{
21 À título exemplificativo, veja-se: ESCLEROSE MÚLTIPLA. Uso de derivados da Cannabis na Esclerose Múltipla. Disponível em: http://esclerosemultipla.com.br/2015/06/24/uso-de-derivados-da-cannabis-na-esclerose-multipla/. Acesso em: 12.10.2018.

22 REIS JUNIOR, Almiro dos. Sigmund Freud (1856-1939) e Karl Köller (1857-1944) e a Descoberta da Anestesia Local. Revista Brasileira de Anestesiologia. v. 59, n. 2, mar.-abr.,2009, p. 245.

23 REIS JUNIOR, Almiro dos. Sigmund Freud..., p. 245

24 FRANÇA, Valenio Pérez. O namoro de Freud e a descoberta da anestesia tópica. Revista Médica de Minas Gerais. v. 20, n. 1, jan./mar., 2010, p. 134-135.

25 REIS JUNIOR, Almiro dos. Sigmund Freud..., p. 251.

26 ONCOGUIA. Medicamentos analgésicos Opioides. Disponível em: http://www.oncoguia.org.br/conteudo/ analgesicos-opioides/7674/902/. Acesso em: 29.09.2018.
} 
com controle. No entanto, os medicamentos na forma líquida ou em xarope pediátrico são proibidos. ${ }^{27}$

Em relação a outra droga, percebe-se larga e crescente discussão acerca do uso da Cannabis Sativa, seja para fins medicinais, seja para fins recreativos. Os primeiros registros do uso desta planta remontam ao ano de 2723 antes de Cristo, quando a Cannabis foi mencionada na Farmacopeia Chinesa. Posteriormente difundindo-se para índia, Oriente Médio e chegando à Europa do final do século XVIII e início do século XIX, a planta era utilizada por suas propriedades têxteis e medicinais. ${ }^{28}$ Outros dados demonstram registros que datam de 2737 a.c., época na qual o imperador chinês ShenNeng prescrevia chá de maconha para tratamento de gota, malária, reumatismo e até memória fraca.

No ano de 1839, o médico britânico William O'Shaughnessy conseguiu utilizar uma tintura canábica para fazer com que uma criança parasse de ter convulsões, surgindo portanto a propriedade anticonvulsivante da planta, o que fez o uso medicinal difundir na Europa. ${ }^{29}$ Já no início do século XX, a planta começou a ser vista de forma preconceituosa por uma elite social, subjugando o uso da Cannabis por conta das minorias sociais que a utilizavam na época, difundindo então a ideia de que a maconha era um mal a ser combatido. ${ }^{30}$

Em 1961 tem-se um marco de combate às drogas com o advento da Convenção Única sobre Entorpecentes da Organização das Nações Unidas, da qual o Brasil é signatário por meio da ratificação da Convenção pelo Decreto n 54.216/1964. Esse documento tem por objetivo o combate ao abuso das drogas, por meio da cooperação internacional e "limitação da posse, do uso, da troca, da distribuição, da importação, da exportação, da manufatura e da produção de drogas exclusivas para uso médico e científico,"31 o que, por outro lado, fez com que o uso medicinal da maconha fosse suprimido. ${ }^{32}$

\footnotetext{
27 Adendo da Lista A1, da Portaria no 344/1998 do ministério da Saúde: "3.preparações a base de ÓPIO contendo não mais que 50 miligramas de ÓPIO (contém 5 miligramas de morfina anidra), ficam sujeitas a VENDA SOB PRESCRIÇÃO MÉDICA SEM A RETENÇÃO DE RECEITA; 4.fica proibida a comercialização e manipulação de todos os medicamentos que contenham ÓPIO e seus derivados sintéticos e CLORIDRATO DE DIFENOXILATO e suas associações, nas formas farmacêuticas líquidas ou em xarope para uso pediátrico (Portaria SVS/MS n. ${ }^{\circ} 106$ de 14 de setembro de 1994 ? DOU 19/9/94)".

28 CENPRE. Histórico da Maconha. Disponível em: http://www.cenpre.furg.br/drogas?id=62. Acesso em: 29.09.2018.

29 ASSOCIAÇÃO BRASILEIRA DE PACIENTES DE CANNABIS MEDICINAL - AMA+ME. Conheça a história da Cannabis Medicinal. Disponível em: https://amame.org.br/historia-da-cannabis-medicinal/. Acesso em: 29.09.2018.

30 ASSOCIAÇÃO BRASILEIRA DE PACIENTES DE CANNABIS MEDICINAL - AMA+ME....

${ }_{31}$ UNODC. Drogas: Marco Legal. Disponível em: http://www.unodc.org/lpo-brazil/pt/drogas/marco-legal. html. Acesso em: 29.09.2018.

32 ASSOCIAÇÃO BRASILEIRA DE PACIENTES DE CANNABIS MEDICINAL - AMA+ME....
} 
A Convenção em si não determina que os países signatários proíbam o cultivo de plantas como a Cannabis Sativa, Erythroxylum coca (folha de coca) ou ainda a $\mathrm{Pa}$ paver somniferum (planta dormideira, uma espécie de papoula utilizada para produzir o ópio), mas estabelece uma série de medidas fiscalizatórias a serem tomadas pelos países que autorizam a produção destas plantas. ${ }^{33}$

Neste sentido, observa-se que a utilização da Cannabis teve desde o início a propositura de um uso para fins medicinais, inclusive com grande avanço desde a descoberta de seu efeito anticonvulsivo. O caráter medicinal dos princípios ativos contidos nessa planta é amplamente comprovado: o tetraidrocanabinol (THC) possui efeito anti-inflamatório, analgésico, sedativo, estimulante, redutor da pressão intraocular; enquanto o canabidiol é utilizado para combater convulsões e epilepsia. ${ }^{34}$

O desenvolvimento do uso terapêutico do canabidiol foi tão importante no âmbito científico biológico que em 14 de janeiro de 2015 a substância foi retirada do rol de substâncias proibidas pela ANVISA, colocando-o na lista de substâncias controladas, ${ }^{35}$ enquanto o Tetraidrocanabinol continua a constar na Lista F-2, n 28, da Portaria n 144/1998. Neste sentido, é relevante ressaltar que a referida Portaria regulamenta a possibilidade de pessoas jurídicas manipularem (latu sensu) tais substâncias em seus artigos $2^{\circ}$ a 10 , no entanto, exclui-se de tal possibilidade os medicamentos e substâncias proscritos por essa normativa, ${ }^{36}$ que é o caso do THC.

33 Estabelece o artigo 23 do Decreto no 54.216/1964: "1. A parte que permitir o cultivo da dormideira para produção de ópio criará, se ainda não o fêz, e manterá um ou mais organismos oficiais (designados daqui por diante neste artigo pelo termo "organismo") para desempenho das funções estipuladas no presente artigo. 2 . A parte em questão aplicará ao cultivo da dormideira para produção do ópio e ao ópio as seguintes disposições: a) o organismo designará as áreas e as porções de terreno que se permitirá o cultivo da dormideira para produção do ópio; b) só poderão dedica-se ao referido cultivo os plantadores que possuam uma licença que expedida pelo organismo; c) Cada licença especificará a extensão do terreno em que é autorizado o cultivo; d) Os plantadores de dormideira serão obrigados a entregar a totalidade de suas colheitas de ópio ao organismo. Êste comprará e tomará posse material das referidas colheitas, o mais depressa possível, o mais tardar quatro meses após a sua terminação. e) Com relação ao ópio caberá ao organismo, com exclusividade, o direito de importar exportar, comerciar por atacado e manter os estoques que não se achem em poder dos fabricantes de alcalóides do ópio, de ópio medicinal e preparados do ópio. Não é necessário que as partes estendam esse direito exclusivo ao ópio medicinal e aos preparados á base de ópio. 3 As funções administrativas a que se refere o parágrafo 2 , serão desempenhadas por único organismo oficial se a Constituição da Parte interessada assim o permitir."

34 SENADO FEDERAL. Neurocientista aponta propriedades medicinais da maconha. Disponível em: https://www12.senado.leg.br/noticias/materias/2014/08/25/neurocientista-aponta-propriedades-medicinais-da-maconha. Acesso em: 29.09.2018.

35 UNASUS. Anvisa retira canabidiol, derivado da maconha, de lista de substâncias proscritas. Disponível em: https://www.unasus.gov.br/noticia/anvisa-tira-canabidiol-derivado-da-maconha-da-lista-de-substancias-proibidas. Acesso em: 29.09.2018.

36 "Art. $4^{\circ}$ Ficam proibidas a produção, fabricação, importação, exportação, comércio e uso de substâncias e medicamentos proscritos. Parágrafo único. Excetuam-se da proibição de que trata o caput deste artigo, as atividades exercidas por Órgãos e Instituições autorizados pela Secretaria de Vigilância Sanitária do Ministério da Saúde com a estrita finalidade de desenvolver pesquisas e trabalhos médicos e científicos." 
Entretanto, em dezembro de 2019, com a aprovação da RDC n³25, a ANVISA passou a permitir a venda de medicamentos que contém Canabidiol e Tetrahidrocannabinol, em concentração máxima de 30 miligramas de cada um dos princípios ativos, de forma controlada. ${ }^{37}$ A normativa que entra em vigor em 90 dias a contar da publicação demonstra, desde logo, um resgate do tema e avanços no âmbito da regulação de medicamentos. O fato em questão é um marco importante para a discussão sobre os fármacos com princípios ativos proibidos, tendo em vista que há possibilidade de revisão do uso de tais substâncias a fim de torná-las mais acessíveis pelo uso controlado medicamentoso, regulamentando as doses corretas sem a necessidade de liberar o uso da substância de forma geral, inclusive para fins recreativos.

Conforme mencionado, a Convenção de 1961 sobre entorpecentes não proibiu a produção destas plantas milenarmente conhecidas por seu uso medicinal, mas apenas delimitou a atuação estatal de modo que o país signatário dessa Convenção que optasse pela liberação da produção regulasse a matéria. A opção por inserir essas fórmulas no rol de proibições foi uma escolha legislativa do Estado brasileiro, não havendo proibição vinculante no âmbito internacional.

Ao contrário, a possibilidade de rever as vedações provenientes de uma política criminal repressiva é uma tendência mundial. ${ }^{38} \mathrm{~A}$ liberação, todavia, não deve ser feita de forma aleatória. Devem ser estabelecidos critérios expressos, claros e congruentes. Nos Estados Unidos da América, a empresa britânica GW Pharmaceuticals é a primeira a receber autorização para comercializar um tratamento derivado de cannabis para graves casos de epilepsia infantil, alcançando uma projeção de vendas no patamar de aproximados $\mathrm{R} \$ 4,5$ bilhões por ano. ${ }^{39}$

No Brasil, a proposta feita pelo Ministro Luis Roberto Barroso (conforme demonstrar-se-á adiante) e recentemente aprovada pelo Supremo Tribunal Federal para concessão de fármacos sem registro na ANVISA deve-se pautar, inclusive, na comprovação da eficácia do medicamento por meio de seu registro em outras renomadas agências reguladoras fora do Brasil. ${ }^{40}$ As pesquisas globais nesta seara estão avançando em proporções geométricas. No entanto, ao passo que o desenvolvimento global da

37 A RDC no 325 assim prevê: "excetuam-se dos controles referentes a esta lista os medicamentos registrados na Anvisa que possuam em sua formulação derivados de Cannabis sativa, em concentração de no máximo 30 $\mathrm{mg}$ de tetrahidrocannabinol (THC) por mililitro e $30 \mathrm{mg}$ de canabidiol por mililitro, desde que sejam atendidas as exigências desta Resolução."

38 Por exemplo, mencione-se: UFJF. Pesquisadores defendem uso medicinal de derivados da maconha. Disponível em: https://www2.uff.br/noticias/2018/02/24/pesquisadores-defendem-uso-medicinal-de-derivados-de-maconha/. Acesso em: 30.09.2018.

39 EL PAÍS. EUA autorizam o primeiro medicamento feito a partir de maconha. Disponível em: https:// brasil.elpais.com/brasil/2018/06/25/actualidad/1529952375_014000.html. Acesso em: 30.09.2018.

40 STF. Recurso Extraordinário n 657.718/MG. Relator: Ministro Marco Aurélio. DJE 12.03.2012. Disponível em: http://www.luisrobertobarroso.com.br/wp-content/uploads/2016/10/RE-657718-Medicamentos-sem-registro -Anvisa-versa\%CC\%83o-final.pdf Acesso em: 30.09.2018. 
pesquisa sobre estes princípios ativos proibidos parece consolidar-se cada vez mais a fim de alcançar novas alternativas para proteção da saúde, no Brasil desenvolve um cenário instável e antagônico. A recente Lei no 13.840, publicada em 05 de junho de 2019, traz em seu texto além de programa para readaptação do usuário de drogas, novas políticas de combate ao uso de entorpecentes de modo a enrijecer a já existente, instituindo inclusive a modalidade de internação involuntária. ${ }^{41}$ Diretrizes como estas, já aprovadas pelo Congresso Nacional, novamente trazem as drogas como um problema social, não como possível alternativa aos tratamentos de saúde obsoletos para muitos pacientes. O retrocesso é evidente e caminha em sentido oposto aos avanços civilizatórios racionais inerentes ao desenvolvimento da ciência.

Por outro lado, apartando-se do Legislativo e Executivo nacionais contemporâneos, a Agência Nacional de Vigilância Sanitária vem apresentado desenvolvimento maior sobre o tema, desde o aumento dos pedidos de importação do canabidiol até a recente consulta pública sobre e a possibilidade de liberação do plantio da Cannabis Sativa para uso medicinal. ${ }^{42}$ Desta forma, resta fortalecida a ideia de serem retomadas as pesquisas, bem como de redeliberação sobre as proibições provenientes da atual política criminal de drogas no Brasil. É altamente desejável, a partir de uma hermenêutica de concretização do Estado Social estabelecido na Constituição de 1988, ser construído um caminho mais acessível aos tratamentos alternativos com uso de substâncias proscritas. Neste cenário é que se insere a RDC 325, por meio da qual a ANVISA reconheceu a existência de finalidades medicamentosas de substância proibida, permitindo a venda de medicamentos a base de THC, afastando-se o plantio de maconha. ${ }^{43}$

Neste sentido, observa-se que o tema dos medicamentos com princípios ativos proibidos vem tomando grande repercussão no âmbito nacional. Em 2014, a Superinteressante lançou seu primeiro curta-metragem, denominado "Ilegal", abordando a luta

\footnotetext{
${ }_{41}$ "Art. 23-A. O tratamento do usuário ou dependente de drogas deverá ser ordenado em uma rede de atenção à saúde, com prioridade para as modalidades de tratamento ambulatorial, incluindo excepcionalmente formas de internação em unidades de saúde e hospitais gerais nos termos de normas dispostas pela União e articuladas com os serviços de assistência social e em etapas que permitam: [...] § $3^{\circ}$ São considerados 2 (dois) tipos de internação: I - internação voluntária: aquela que se dá com o consentimento do dependente de drogas; II - internação involuntária: aquela que se dá, sem o consentimento do dependente, a pedido de familiar ou do responsável legal ou, na absoluta falta deste, de servidor público da área de saúde, da assistência social ou dos órgãos públicos integrantes do Sisnad, com exceção de servidores da área de segurança pública, que constate a existência de motivos que justifiquem a medida."

42 ANVISA. Notícias sobre regulação. Disponível em: http://portal.anvisa.gov.br/noticias13?tagsName=canabidiol. Acesso em: 14 de junho de 2019.

43 "Por três votos a um, a proposta que previa autorizar o cultivo de maconha pelas empresas produtoras dos medicamentos à base de cannabis foi rejeitada. O relator Willian Dib, diretor-presidente da Anvisa, foi o único a votar a favor." In: EXAME. Anvisa regulamenta medicamentos à base de maconha, mas rejeita cultivo. Disponível em: https://exame.abril.com.br/brasil/anvisa-aprova-regulamentacao-de-medicamentos-a-base-de-maconha/. Acesso em 06 de dezembro de 2019.
} 
de pacientes pela legalização da maconha medicinal no Brasil. ${ }^{44} \mathrm{~A}$ inspiração para desenvolvimento do documentário foi a história de Katiele Bortoli Fischer, que buscava a importação de canabidiol para sua filha Anny (5 anos), que possui uma síndrome que desencadeia um tipo grave e sem cura de epilepsia, tendo diversas crises de convulsões (até 80 por semana). A dificuldade enfrentada pela família na burocracia para importação do fármaco volta-se ainda ao combate do preconceito e desinformação sobre o uso de remédios à base de Cannabis.

No documentário, demonstra-se a seriedade do acompanhamento médico que indica a inexistência de outro tratamento eficaz para casos como o de Anny e a dificuldade de obter um tratamento como este, haja vista que até então o médico que prescrevesse medicamento à base de maconha poderia perder seu registro no Conselho Federal de Medicina. Outro aspecto relevante do documentário envolve a busca pela liberação da substância pela via legislativa: as mães de pacientes que necessitavam utilizar tais fármacos foram até Brasília a fim de conquistar a liberação apenas para fins medicinais por meio de Lei, entretanto a inércia dos deputados, o preconceito, ou ainda diferenças de interesse obstaram a conquista por intermédio da Câmara de Deputados. ${ }^{45}$

A situação demonstrada no curta-metragem inspirou ainda o "Repense", 46 uma campanha para incentivar o debate e as reflexões sobre o uso medicinal da maconha no Brasil. ${ }^{47}$ Ainda conforme demonstrado no documentário, houve a mobilização de várias famílias que sofriam com casos parecidos com o de Anny em passeatas e manifestações sobre o uso medicinal da "droga", abrangendo cada vez mais tratamentos não só à base de canabidiol, mas também do outro princípio ativo extraído da planta, o tetraidrocanabinol. ${ }^{48}$

Todo esse aparelhamento e estudo sobre o uso medicinal da Cannabis fez com que a ANVISA anunciasse no $4^{\circ}$ Simpósio Internacional da Cannabis Medicinal a aprovação da reclassificação do canabidiol (CBD), retirando-o da lista de substâncias proscritas (F1) para a lista $C 1$, que permite a prescrição médica com receita normal em duas

\footnotetext{
44 SUPERINTERESSANTE. Ilegal. 2014. Disponível em: https://www.youtube.com/watch?v=6PPUY69 4Csc. Acesso em: 12.10.2018.

45 Observa-se no documentário que alguns parlamentares afirmaram ser possível a distinção e liberação do canabidiol apenas para fins medicinais, enquanto outros pretendiam a liberação da Cannabis, afirmando não ser possível tal separação.

46 SUPERINTERESSANTE. Ilegal: primeiro filme da SUPER mostra a luta de pacientes pela legalização da maconha medicinal no Brasil. Disponível em: https://super.abril.com.br/blog/superblog/ilegal-primeiro -filme-da-super-mostra-a-luta-de-pacientes-pela-legalizacao-da-maconha-medicinal-no-brasil/. Acesso em: 12.10.2018.

47 CATARSE. Repense: campanha de conscientização sobre a maconha medicinal. Disponível em: https:// www.catarse.me/repense. Acesso em: 12.10.2018.

48 O curta-metragem traz vários exemplos do uso do THC, inclusive para diminuição da dor de pacientes com esclerose e também para diminuir os efeitos da quimioterapia.
} 
vias. ${ }^{49}$ Diante deste cenário, em 2015 a substância foi efetivamente retirada do rol de substância proscritas, a fim de facilitar o uso do CBD para tratamentos. ${ }^{50} \mathrm{~A}$ ANVISA elaborou um procedimento administrativo para facilitação da solicitação de importação de canabinóides. O Procedimento foi criado pela Resolução de Diretoria Colegiada nº 17 de 6 de maio de 2015, consistindo nas seguintes etapas para importação de canabinóides: consulta médica e prescrição, cadastramento de pacientes na ANVISA, análise do pedido, autorização para importação, aquisição e importação do produto e, por último, fiscalização e liberação na importação pela ANVISA. ${ }^{51}$ No entanto, há de se ressaltar dois pontos em relação ao procedimento administrativo: $:^{52}$ o primeiro deles é de que a RDC não prevê prazo para finalização do processo, ou seja, o particular fica à mercê da apreciação do pedido Agência Reguladora, podendo se estender mais do que a saúde do paciente permite; ainda, a própria RDC prevê a possibilidade de concessão para autorização, por prazo máximo de 1 ano, ainda em caráter de excepcionalidade, conforme seu artigo $12 .{ }^{53}$

A discussão toda se volta para proteção do direito à saúde sob a óptica de substâncias primariamente dispensadas ou mal vistas, porém com grande potencial de amenização de sintomas, senão até a cura. Não parece razoável supor que tais substâncias devem ser extirpadas em todos os âmbitos, inclusive na medicina, simplesmente por estarem previstas na lista F da Portaria no 344/1998. Ademais, no início de 2017, a Agência Nacional de Vigilância Sanitária registrou o medicamento Mevatyl ${ }^{\circledR}$, o primeiro do país à base de Cannabis Sativa (princípios ativos: tetraidrocanabinol e canabidiol), cujo propósito é tratar espasticidade de pacientes portadores de Esclerose Múltipla. ${ }^{54}$ Portanto, reconhecendo a necessidade do tratamento, este registro é um marco importante no tema das substâncias proscritas, haja vista que um dos princípios ativos deste medicamento (tetraidrocanabinol) ainda consta como substância de uso proscrito na Portaria n³44/1998 do Ministério da Saúde.

49 ARAÚJO, Tarso. Agora é Oficial: ANVISA vai liberar a prescrição de CBD. Disponível em: https://super.abril. com.br/blog/psicoativo/agora-e-oficial-anvisa-vai-liberar-a-prescricao-de-cbd/. Acesso em: 12.10.2018.

50 CALZOLARI, Izabella. Anvisa decide retirar o canabidiol da lista de substâncias de uso proibido. Disponível em: http://g1.globo.com/bemestar/noticia/2015/01/anvisa-decide-retirar-o-canabidiol-da-lista-de-substancias-de-uso-proibido.html. Acesso em: 12.10.2018.

51 ANVISA. Orientações sobre importação de canabidiol. Disponível em: http://portal.anvisa.gov.br/importacao-de-canabidiol. Acesso em: 12.10.2018.

52 Note-se que a disposição regulamentar é aqui tratada como um avanço significativo para o tema, mas que ainda apresenta falhas em decorrência da necessidade de uma estrutura sólida e organizada para alcançar um patamar ótimo de desenvolvimento.

53 "Art. 12 Somente após a aprovação do cadastro, o interessado poderá realizar as importações do produto à base de Canabidiol, em associação com outros canabinóides, dentre eles o THC, constante do Anexo I desta Resolução, em caráter de excepcionalidade, pelo período de 1 (um) ano."

54 ANVISA. Registrado primeiro medicamento à base de Cannabis Sativa. Disponível em: http://portal. anvisa.gov.br/noticias/-/asset_publisher/FXrpx9qY7FbU/content/agencia-aprova-primeiro-remedio-a-base-de-cannabis-sativa/219201. Acesso em: 02.06.2018. 
O uso dos princípios ativos da planta para tratamentos médicos é cada vez mais crescente: pacientes com Epilepsia, Síndrome de Parkinson, Microcefalia e diversas outras doenças buscam diariamente para conseguir autorização e fazer uso da planta in natura ou de seus medicamentos derivados. ${ }^{55}$ Especificamente em relação à molécula que é proibida no Brasil (THC), há comprovação de sua eficácia como recurso terapêutico para a redução das náuseas, vômitos e dor para pacientes que estão se submetendo a sessões de quimioterapia para cura do câncer, especialmente aqueles que não respondem aos antieméticos normais. ${ }^{56} \mathrm{~A}$ inclusão da Cannabis medicinal para pacientes inscritos no programa de medicina paliativa demonstrou que há melhora nos sintomas decorrentes do tratamento oncológico tais como cansaço, sonolência, depressão, náusea, apetite e até ansiedade. ${ }^{57}$

Cite-se alguns remédios que possuem THC e eficácia comprovada fora do Brasil, bem como sua indicação: Marinol (Dronabinol, THC sintético), aprovado nos EUA para amenizar perda de apetite associada ao HIV e também para os sintomas reflexos da quimioterapia; CESAMET (Nabilona, canabinóide sintético semelhante ao THC), liberado nos EUA, Canadá, Reino Unido e México para combater os sintomas da quimioterapia, também para anorexia e perda de peso de pacientes com HIV e atua como analgésico para dores neuropáticas para pacientes com fibromialgia e esclerose múltipla; SATIVEX (THC e CBD provenientes do extrato de Cannabis Sativa), aprovado no Canadá, Reino Unido e Espanha, com a finalidade de tratamento de esclerose múltipla e glaucoma; BEDROCAN (THC e CBD), criado na Holanda - variando os percentuais dos princípios ativos pode ser utilizado para tratamento de convulsões e glaucoma. ${ }^{58}$

A utilização de um princípio ativo proibido como o tetraidrocanabinol pode impactar significativamente no tratamento de diversas doenças, razão pela qual tanto a Administração Pública quanto o Poder Judiciário devem observar tais terapias alternativas buscando proteger efetivamente o direito à saúde do cidadão. A possibilidade da Administração Pública conceder autorização para importação desses medicamentos consubstancia-se no fato de que já o fazia com o canabidiol antes desta substância ser liberada, bem como no fato de já ter registrado medicamento com princípio ativo proibido, conforme demonstrado. Posteriormente, a RDC 325 justamente autoriza a venda

\footnotetext{
55 ALAGOAS 24 HORAS. Remédio à base de maconha ajuda no tratamento de doenças neurológicas. Disponível em: http://www.alagoas24horas.com.br/1147351/remedio-base-de-maconha-ajuda-tratamento-de-doencas-neurologicas/. Acesso em: 12.10.2018.

56 ASSOCIAÇÃO BRASILEIRA DE PACIENTES DE CANNABIS MEDICINAL - AMA+ME. Suporte à quimioterapia potencial terapêutico. Disponível em: https://amame.org.br/cannabis/suporte-a-quimioterapia/. Acesso em: 12.10.2018.

57 ASSOCIAÇÃO BRASILEIRA DE PACIENTES DE CANNABIS MEDICINAL - AMA+ME. Suporte à quimioterapia... Acesso em: 12.10.2018.

58 GAUCHAZH. Conheça os remédios que contam com substâncias advindas da maconha. Disponível em: https://gauchazh.clicrbs.com.br/saude/vida/noticia/2014/05/Conheca-os-remedios-que-contam-com-substanc ias -advindas-da-maconha-4503256.html. Acesso em: 12.10.2018.
} 
de medicamentos com CDB e THC de forma controlada, de modo a corroborar com tal tese e demonstrar a possibilidade de se ter uma regulamentação administrativa mais efetiva.

Em que pese a discussão voltar-se até o momento sobre os derivados da Cannabis, não se exclui a possibilidade de utilização de outras substâncias proscritas para fins medicinais, tais como: Etretinato (derivado da vitamina A) medicamento desenvolvido pela empresa Hoffman-La Roche e aprovado nos EUA desde 1986, ${ }^{59}$ para o tratamento de psoríase grave; ${ }^{60}$ fármacos com opioides, tais como Fentanil (Actiq e Sublimaze), indicados para tratamento de dor irruptiva de pacientes em terapia oncológica; ${ }^{61}$ ou até mesmo fármacos com base de psilocibina, molécula extraída de cogumelos alucinógenos que pode ser utilizada para tratamento de depressão aguda, conforme pesquisa desenvolvida pela Imperial College London. ${ }^{62}$

Assim, observa-se que há ampla possibilidade de utilização destas substâncias inseridas na lista F da Portaria no 344/1998 do Ministério da Saúde para fins medicinais, pelo que não há de se restringir seu uso nestes casos, especialmente aos pacientes que necessitam urgentemente destas substâncias. Por outro lado, há de se observar determinados critérios que delimitem a concessão destas substâncias, haja vista que a proposta é o uso terapêutico e não recreativo.

\section{CRITÉRIOS PARA CONCESSÃO DE MEDICAMENTOS SEM REGIS- TRO NA ANVISA}

O Ministério da Saúde publica periodicamente a atualização da Relação Nacional de Medicamentos Essenciais (RENAME), os quais compõem uma lista de orientação para a assistência farmacêutica a ser seguida pelos entes da Federação. A título exemplificativo, da análise do RENAME de 2018, observa-se que nenhum os medicamentos anteriormente mencionados (Sativex, Marinol, Cesamet e Bedrocan) ou alguns de seus princípios ativos (THC e CBD, provenientes da Cannabis Sativa) constam naquela lista. ${ }^{63}$ Por esta razão, ressalte-se que aquele que postula o fornecimento de um fármaco com

\footnotetext{
59 LOPES, Antônio Carlos (Ed.). Diagnóstico e tratamento. v. 2. Barueri: Manole, 2006, p. 401.

60 ÍNDICE. Etretinato. Disponível em: https://www.indice.eu/pt/medicamentos/DCl/etretinato/informacao -geral. Acesso em: 12.10.2018.

61 AQTIC. Indications and Usage. Disponível em: http://www.actiq.com/. Acesso em: 12.10.2018.

62 O'HARE, Ryan. Magic mushrooms may 'reset' the brains of depressed patients. Imperial College of Science, Technology and Medicine. Disponível em: https://www.imperial.ac.uk/news/182410/magic-mushrooms-reset-brains-depressed-patients/. Acesso em: 8 de junho de 2019.

63 BRASIL. Ministério da Saúde. Secretaria de Ciência, Tecnologia e Insumos Estratégicos. Departamento de Assistência Farmacêutica e Insumos Estratégicos. Relação Nacional de Medicamentos Essenciais: RENAME 2018. Ministério da Saúde, Secretaria de Ciência, Tecnologia e Insumos Estratégicos, Departamento de Assistência Farmacêutica e Insumos Estratégicos. - Brasília: Ministério da Saúde, 2018. Disponível em: https://www. conass.org.br/wp-content/uploads/2018/11/RENAME-2018.pdf. Acesso em: 8.06.2019.
} 
princípio ativo proscrito postula simultânea e consequentemente um medicamento não fornecido pelo SUS.

Assim sendo, diante de reiteradas demandas sobre medicamentos que não constam nas listas do SUS, o Superior Tribunal de Justiça decidiu pela afetação do Recurso Especial no 1.657.156/RJ ao rito previsto no art. 1.036 do Código de Processo Civil, instaurando procedimento de Recursos Especiais Repetitivos (tema no 106). O referido Tribunal optou também pela decisão em que pudesse fixar parâmetros jurisprudenciais a serem observados pelos magistrados quando do julgamento de demandas que pleiteiam medicamentos não abarcados no RENAME. Em 4 de maio de 2018 o Tribunal procedeu ao julgamento do tema sobre a obrigatoriedade do poder público de fornecer medicamentos não incorporados em atos normativos do SUS, fixando a tese de que deve haver comprovação da imprescindibilidade do tratamento e ineficácia dos tratamentos fornecidos pelo SUS, demonstração de incapacidade financeira do cidadão, bem como existência de registro na ANVISA do medicamento pleiteado. ${ }^{64}$ É possível resumir em três os requisitos: 1 . comprovação da necessidade do fármaco, 2 incapacidade financeira da parte e 3. registro do medicamento na ANVISA.

Até o julgamento da Repercussão Geral no 500 pelo Supremo Tribunal Federal, a fixação de tais parâmetros trouxe dois posicionamentos divergentes na jurisprudência: primeiramente, alguns julgadores optaram pelo entendimento de que os fármacos sem registro na ANVISA não poderiam ser concedidos na via judicial, tendo em vista a exigência do registro constar dentre os requisitos previstos pelo Superior Tribunal de Justiça,;5 outros, em contraposição, compreenderam pela possibilidade (em casos

64 "4. TESE PARA FINS DO ART. 1.036 DO CPC/2015: A concessão dos medicamentos não incorporados em atos normativos do SUS exige a presença cumulativa dos seguintes requisitos: (i) Comprovação, por meio de laudo médico fundamentado e circunstanciado expedido por médico que assiste o paciente, da imprescindibilidade ou necessidade do medicamento, assim como da ineficácia, para o tratamento da moléstia, dos fármacos fornecidos pelo SUS; (ii) incapacidade financeira de arcar com o custo do medicamento prescrito; (iii) existência de registro na ANVISA do medicamento." In: STJ. Recurso Especial n 1.657.156/RJ. Rel. Ministro Benedito Gonçalves, julgado em 25/04/2018, DJe 04/05/2018

65 Observe-se, por exemplo, o seguinte julgado do Tribunal Regional Federal da 4a Região: “AGRAVO DE INSTRUMENTO. FORNECIMENTO DE MEDICAMENTO. ETEPLIRSEN (EXONDYS ${ }^{\circledR}$ ).DISTROFIA MUSCULAR DO TIPO DUCHENNE (DMD). MEDICAMENTO NÃO REGISTRADO NA ANVISA. REQUISITOS AUSENTES. 1. A Constituição Federal de 1988, após arrolar a saúde como direito social em seu artigo 6, estabelece, no art. 196, que a saúde é "direito de todos e dever do Estado", além de instituir o"acesso universal e igualitário às ações e serviços para sua promoção, proteção e recuperação". 2. O Supremo Tribunal Federal fixou, no julgamento da Suspensão de Tutela Antecipada n. 175 (decisão da Corte Especial no Agravo Regimental respectivo proferida em 17 de março de 2010, Relator o Ministro Gilmar Mendes), alguns pressupostos e critérios relevantes para a atuação do Poder Judiciário no tema da saúde, mais precisamente na questão do fornecimento de medicamentos e tratamentos pleiteados em face dos Entes Políticos. 3. Recentemente, a 1a Seção do STJ, ao julgar o recurso repetitivo (REsp n 1.657.156), definiu os critérios para fornecimento de medicamentos não incorporados em atos normativos do SUS, exigindo, para tanto, a presença cumulativa dos seguintes requisitos: comprovação por meio de laudo médico fundamentado e circunstanciado expedido por médico que assiste o paciente da imprescindibilidade ou necessidade do medicamento, assim como da ineficácia, para o tratamento da moléstia, dos fármacos fornecidos pelo SUS; incapacidade financeira de arcar com o custo de medicamento prescrito; e existência de registro na Anvisa do medicamento. 4. Hipótese em que, comprovadamente, o medicamento 
excepcionais) de o Poder Judiciário viabilizar o fornecimento de fármacos sem registro, eis que tal emento não é impeditivo para concretização do direito fundamental à saúde. ${ }^{6}$

Assim, tais requisitos não foram suficientes para abarcar as várias solicitações de fármacos em diferentes situações de judicialização, o que ressaltou ainda mais a imprescindibilidade da fixação de uma tese única para cada caso. Por exemplo: para medicamentos que não constam nas listas de fornecimento do SUS, tem-se a fixação de uma tese pelo Superior Tribunal de Justiça nos moldes de recursos repetitivos com o tema no 106; também recentemente julgada, para os medicamentos de alto custo, o Supremo Tribunal Federal fixou a Repercussão Geral n 6, com a fixação de outros critérios; já para medicamentos não registrados na ANVISA, tem-se a Repercussão Geral n 500. Observa-se, portanto, que na própria jurisprudência há a subdivisão dos temas que envolvem a concessão de medicamentos pela via judicial, reconhecendo desde logo a existência de situações diferentes, levando em consideração as especificidades dos casos que levaram à judicialização.

Nesta seara, dentre os medicamentos solicitados demandados pela população, vários deles não possuem registro na Agência Nacional de Vigilância Sanitária, pelo que a alternativa restante para sua concessão é a via judicial. Cite-se como exemplo o fármaco lomitapida, que não possui registro na Agência responsável e, portanto, não está incluído na Relação Nacional de Medicamentos Essenciais - RENAME e não compõe nenhum Programa de Assistência Farmacêutica do Sistema Único de Saúde. ${ }^{67}$ Entretanto, na lista dos medicamentos sem registro mais pedidos judicialmente (2015), tal medicamento alcança o segundo lugar, com a despesa de mais de $\mathrm{R} \$ 41$ milhões a ser arcada pela União. ${ }^{68}$

Esclareça-se que a análise em questão é de extrema importância para os medicamentos que possuem princípio ativo proscrito no Brasil, haja vista que a Portaria ${ }^{\circ}$

não possui registro na ANVISA. 5. Ausentes os pressupostos indispensáveis para a concessão da antecipação dos efeitos da tutela pretendida, nos termos do artigo 300 do CPC." In: TRF4, AG 5006987-51.2019.4.04.0000, Turma Regional Suplementar do Paraná, Relator Marcos Josegreidi da Silva. Juntado aos autos em 23/05/2019.

66 "AGRAVO DE INSTRUMENTO. ADMINISTRATIVO. FORNECIMENTO DE MEDICAMENTO. MEDICAMENTO NÃO REGISTRADO NA ANVISA. NÃO IMPEDITIVO. CASOS EXCEPCIONAIS. MEDICAMENTOS INDISPENSÁVEIS. 1. O fato de o medicamento não estar registrado na ANVISA não impede o Poder Judiciário - em casos excepcionais - determinar que o Estado forneça-o à parte que dele necessita. 2. Comprovado que os medicamentos são indispensáveis ao tratamento da enfermidade que acomete o(a) autor(a) e a inexistência de outra alternativa terapêutica, é inafastável o reconhecimento de seu direito à tutela jurisdicional." In: TRF4, Agravo 5010857-41.2018.4.04.0000, quarta turma, Relatora Des. Vivian Josete Pantaleão Caminha, juntado aos autos em 25/06/2018.

67 AGU. Manifestação Jurídica Referencial sobre o medicamento Lomitapida. Disponível em: http://portalarquivos2.saude.gov.br/images/pdf/2017/maio/31/0001-2017-lomitapida.pdf. Acesso em: 12.09.2018.

68 AGU. Judicialização da saúde no Brasil: Principais Projetos Desenvolvidos pela Coordenação de Assuntos Judiciais. Disponível em: http://portalarquivos2.saude.gov.br/images/pdf/2017/maio/17/JUDICIALI ZACAO\%20DA\%20SAUDE\%20NO\%20BRASIL\%20Principais\%20Projetos\%20Desenvolvidos\%20pela\%20Coordenacao\%20de\%20Assuntos\%20Judiciais.pdf Acesso em: 10.09.2018. 
344/1998 prevê a possibilidade de concessão de autorização especial para pesquisa com as substâncias contidas na Lista $\mathrm{F}^{69}$ mas proíbe a prescrição médica para tratamentos alopáticos ou homeopáticos. ${ }^{70}$

A crescente demanda pelos medicamentos sem registro na ANVISA fez com que o Supremo Tribunal Federal reconhecesse a importância do tema na Repercussão Geral de número 500 (Recurso Extraordinário n 657.718), a fim de estabelecer parâmetros para o fornecimento judicial de tais medicamentos não registrados. Primeiramente, o recurso paradigma em questão foi julgado extinto sem a resolução do mérito, ${ }^{71}$ com fundamento no art. 485, IX do Código de Processo Civil, ${ }^{72}$ não impedindo o prosseguimento da análise, cuja Repercussão Geral fora anteriormente reconhecida. Através do julgamento do tema, inicialmente o Ministro Luís Roberto Barroso publicou em 2016 a sua proposta de voto, estabelecendo novos critérios para a concessão de medicamentos sem registro na ANVISA. ${ }^{73} \mathrm{O}$ Ministro dividiu a análise da concessão dos medicamentos sem registro em dois cenários. O primeiro deles envolve os fármacos experimentais (sem eficácia comprovada), cujo fornecimento e importação pela via judicial não podem ser concedidos, conforme entendimento do Ministro. O segundo cenário abarca os medicamentos sem registro na ANVISA, mas com eficácia comprovada, os quais podem ser fornecidos judicialmente em caso de irrazoável mora da ANVISA em apreciar o pedido de registro do medicamento, por mais de 365 dias, devendo preencher os seguintes requisitos: 1. medicamento submetido a registro no Brasil, sem que tenha havido qualquer manifestação pela negativa de registro pela Anvisa; 2. ausência de substituto terapêutico registrado na agência em questão; 3. registro em renomadas agências reguladoras fora do Brasil. Apesar de não ter elencado na lista de requisitos,

\footnotetext{
69 "Art. $4^{\circ}$ Ficam proibidas a produção, fabricação, importação, exportação, comércio e uso de substâncias e medicamentos proscritos. Parágrafo único. Excetuam-se da proibição de que trata o caput deste artigo, as atividades exercidas por Órgãos e Instituições autorizados pela Secretaria de Vigilância Sanitária do Ministério da Saúde com a estrita finalidade de desenvolver pesquisas e trabalhos médicos e científicos. Art. $5^{\circ} \mathrm{A}$ Autorização Especial é também obrigatória para as atividades de plantio, cultivo, e colheita de plantas das quais possam ser extraídas substâncias entorpecentes ou psicotrópicas. $§ 1^{\circ} \mathrm{A}$ Autorização Especial, de que trata o caput deste artigo, somente será concedida à pessoa jurídica de direito público e privado que tenha por objetivo o estudo, a pesquisa, a extração ou a utilização de princípios ativos obtidos daquelas plantas."

70 "Art. 61. As plantas constantes da lista "E" (plantas que podem originar substâncias entorpecentes e/ou psicotrópicas) e as substâncias da lista " $F$ " (substâncias de uso proscrito no Brasil), deste Regulamento Técnico e de suas atualizações, não poderão ser objeto de prescrição e manipulação de medicamentos alopáticos e homeopáticos."

71 Conforme consulta processual ao site do Supremo Tribunal Federal, em 12.09.2018, disponível em: http:// www.stf.jus.br/portal/jurisprudenciaRepercussao/verAndamentoProcesso.asp?incidente $=4143144 \&$ numeroProcesso $=657718 \&$ classeProcesso $=$ RE $\&$ numeroTema $=500$.

72 "Art. 485. O juiz não resolverá o mérito quando: [...] IX - em caso de morte da parte, a ação for considerada intransmissível por disposição legal."

73 STF. Recurso Extraordinário n 657.718/MG. Relator: Ministro Marco Aurélio. DJE 12.03.2012. Disponível em: http://www.luisrobertobarroso.com.br/wp-content/uploads/2016/10/RE-657718-Medicamentos-sem-registro -Anvisa-versa\%CC\%83o-final.pdf. Acesso em: 13.09.2018.
} 
o Ministro Barroso ainda determinou que "Preenchidos tais requisitos, o Estado deverá viabilizar a importação do fármaco, mas somente deverá custeá-lo quando demonstrada a hipossuficiência do requerente. Nos demais casos, o próprio requerente deverá arcar com os custos envolvidos no processo". ${ }^{74}$ Por último, indicou que as ações que pretendem o fornecimento de fármacos sem registro devem ser propostas em face da União, haja vista que o requisito essencial é a mora de registro por uma agência reguladora federal.

Dentre tais requisitos e apontamentos levantados pelo Ministro, num primeiro momento, merece especial atenção a necessidade da mora na apreciação do pedido de registro por mais de 365 dias pela agência responsável. Tal requisito é tão irrazoável que no próprio Leading case da repercussão geral ocorreu justamente o que se pretende evitar com a concessão judicial dos medicamentos: Alcirene Oliveira, a autora da ação que buscava medicamento sem registro na Anvisa, faleceu em dezembro de 2017 e, mesmo que não tenha sido exclusivamente em razão da doença que lhe acometia, o caso demonstra também a mora judicial em um processo que já estava em andamento há sete anos. ${ }^{75} \mathrm{~A}$ ideia de se fixar um prazo mínimo de 365 dias para que a Anvisa não tenha observado o pedido de registro não é favorável ao paciente e muito menos à tutela do direito à saúde e à vida, pois faticamente o que se conclui é que a análise feita pela Anvisa não é adequada e muito menos tempestiva, razão pela qual o procedimento de aguardar o registro não é compatível com as necessidades dos pacientes que precisam destes novos fármacos para tratamento. ${ }^{76}$ Por outro lado, o que o Supremo Tribunal Federal pretende é salvaguardar um patamar mínimo de segurança jurídica nas demandas desses fármacos.

Um ponto obscuro da proposta referida era sobre a possibilidade de concessão de tais medicamentos em sede de tutela antecipatória, o que por si só supriria a necessidade de se aguardar tal lapso temporal, podendo estabelecer de pronto um tratamento inicial com o fármaco requerido e, posteriormente, ser confirmada ou não a obrigação de prestação estatal no julgamento final do mérito.

A tese final aprovada pelo Supremo Tribunal Federal excluiu o requisito temporal de mora anteriormente proposto, suprimindo a imposição de espera pelo cidadão que pleiteia o medicamento. Portanto, após a deliberação dos Ministros, o Supremo Tribunal Federal fixou a seguinte tese sobre a concessão de fármacos sem registro na ANVISA: "Não se pode obrigar o Estado a fornecer medicamentos experimentais;

74 STF. Recurso Extraordinário n 657.718/MG. Relator: Ministro Marco Aurélio. DJE 12.03.2012. Disponível em: http://www.luisrobertobarroso.com.br/wp-content/uploads/2016/10/RE-657718-Medicamentos-sem-registro -Anvisa-versa\%CC\%83o-final.pdf, p.23. Acesso em: 13.09.2018.

75 MUNIZ, Mariana. Morre autora de ação no STF sobre fornecimento de remédio sem registro na Anvisa. Disponível em: https://www.jota.info/dados/rui/morre-autora-de-acao-no-stf-sobre-fornecimento-de-remedio-sem-registro-na-anvisa-19062018. Acesso em: 17.09.2018;

76 RAYMUNDO, Giseli Valezi. A crise política de medicamentos no Brasil. Curitiba: Prismas, 2017. p. 195-196. 
a inexistência de registro na ANVISA impede o fornecimento pela via judicial, via de regra; é possível o fornecimento de tais medicamentos por meio de decisão judicial, desde que comprove-se a existência de pedido de registro do medicamento no Brasil, a existência de registro do remédio em renomadas agências de regulação internacionais e a inexistência de substituto terapêutico com registro." A tese condicionou, ainda, o ajuizamento das ações que visam o fornecimento de medicamento sem registro em face da União. ${ }^{77}$

Assim, em relação à aprovação da ANVISA, basta que haja solicitação de registro do medicamento, não havendo mais prazo de mora para pleitear o medicamento judicialmente. Persistiram, deste modo, a imprescindibilidade da existência de registro em renomadas agências reguladoras internacionais e a inexistência de substituto terapêutico com registro no Brasil. Novamente, reafirmou-se a legitimidade passiva da União para tais casos.

Em relação a estes outros parâmetros fixados no julgamento da Repercussão Geral n 500, destaca-se a comprovação da eficácia do medicamento por meio de seu registro em outras renomadas agências reguladoras fora do Brasil. Num primeiro momento, o relator do caso (Ministro Marco Aurélio) havia proferido seu voto pela impossibilidade de o Estado fornecer medicamentos sem registro. Em posterior oportunidade, aditou seu voto também concordando com o Ministro Barroso no sentido de que "medicamentos não registrados no Brasil, mas devidamente testados e certificados no exterior podem ser fornecidos pelo Poder Público", limitando o fornecimento às pessoas em situação de vulnerabilidade financeira e à comprovação da indispensabilidade do fármaco. ${ }^{78}$

Em verdade, trata-se do ponto central do debate, haja vista que este critério deveria ser o elemento norteador para o provimento do pedido. Em que pese o art. $24 \mathrm{da}$ Lei $n^{\circ} 6.360 / 76$ possibilitar a prescrição e uso experimental de medicamentos, ${ }^{79}$ é certo

\footnotetext{
77 "1.O Estado não pode ser obrigado a fornecer medicamentos experimentais. 2. A ausência de registro na ANVISA impede, como regra geral, o fornecimento de medicamento por decisão judicial. 3. É possível, excepcionalmente, a concessão judicial de medicamento sem registro sanitário, em caso de mora irrazoável da ANVISA em apreciar o pedido (prazo superior ao previsto na Lei no 13.411/2016), quando preenchidos três requisitos: (i) a existência de pedido de registro do medicamento no Brasil (salvo no caso de medicamentos órfãos para doenças raras e ultrarraras); (ii) a existência de registro do medicamento em renomadas agências de regulação no exterior; e (iii) a inexistência de substituto terapêutico com registro no Brasil. 4. As ações que demandem fornecimento de medicamentos sem registro na ANVISA deverão necessariamente ser propostas em face da União"In:STF. RExt 657718 - Tema de Repercussão Geral n 500. Ministro Relator Marco Aurélio. Ata n 17, de 21/05/2019. DJE n 117, divulgado em 31/05/2019. Disponível em: http://www.stf.jus.br/portal/juris prudenciaRepercussao/verAndamentoProcesso.asp?incidente $=4143144 \&$ numeroProcesso $=657718 \&$ classeProcesso=RE\&numeroTema=500. Acesso em: 8.06.2019.
}

78 GRILLO, Breno. Marco Aurélio complementa voto em julgamento sobre fornecimento de remédios. Disponível em: https://www.conjur.com.br/2016-set-28/pedido-vista-suspende-julgamento-obrigacao-fornecer -remedio Acesso em: 18.09.2018.

79 "Art. 24. Estão isentos de registro os medicamentos novos, destinados exclusivamente a uso experimental, sob controle médico, podendo, inclusive, ser importados mediante expressa autorização do Ministério da 
que a exigência de expressa autorização do Ministério da Saúde torna essa hipótese de excepcional insurgência, ${ }^{80}$ também pelo fato de que o parágrafo único desse mesmo artigo prevê a isenção do registro por prazo máximo de três anos, portanto uma solução de curta duração e em casos extraordinários. Neste enfoque, é necessário dizer que os requisitos em questão - demonstração da eficácia e da necessidade do tratamento pleiteado - devem ser respeitados na concessão de medicamentos com princípios ativos proibidos no Brasil, garantindo a tutela efetiva do direito à saúde e eliminando riscos ao demandante.

Por outro lado, o que se conclui é que tais parâmetros fixados pelo Supremo Tribunal Federal ainda não estão aptos a atender a necessidade sociais das demandas por fármacos, sejam eles sem registro na ANVISA, mas com eficácia comprovada, sejam os que possuem princípio ativo proibido no Brasil que estão incluídos neste rol. ${ }^{81} \mathrm{Em}$ que pese o critério de mora da ANVISA ter sido retirado da tese de Repercussão Geral, a solicitação de registro depende diretamente da empresa farmacêutica que fabrica o fármaco pleiteado, eis que a primeira etapa para o registro de medicamentos novos é a regularização sanitária da empresa. ${ }^{82}$ Segue-se ainda um grande encadeamento de atos que pode resultar no deferimento ou indeferimento do pedido e, portanto, é procedimento também moroso. Há clara necessidade de observância da razoabilidade para resposta à demanda formulada por pedido administrativo dos cidadãos, especialmente quando se trata de direitos fundamentais sociais, como é o caso do direito à saúde e à vida. ${ }^{83}$ Coloca-se, portanto, a imprescindibilidade do medicamento para o

Saúde. Parágrafo único. A isenção prevista neste artigo só será válida pelo prazo de até 3 (três) anos, findo o qual o produto ficará obrigado ao registro, sob pena de apreensão determinada pelo Ministério da Saúde."

80 RAYMUNDO, Giseli Valezi. A crise política de medicamentos no Brasil ..., p. 196.

81 Por este motivo (o afastamento das necessidades e debates da sociedade civil), as decisões do STF são muitas vezes criticadas pela doutrina. Cf.: "No STF, o debate é muito menor, já que o processo é muito mais simples. Um relator apresenta seu voto, na maior parte das vezes não sujeito a maiores discussões prévias (as audiências públicas ocorrem raras vezes) e é seguido ou não pelos demais ministros, que podem pedir vista dos autos e apresentar votos mais elaborados, concordando ou discordando do relator. (...) Nessa discussão, pode-se chegar a conclusões de que a Constituição já previra implicitamente certos direitos e que eles devem ser implementados independentemente de previsão legal expressa." In: LIMA, Edilberto Pontes. O STF e o equilíbrio federativo: entre a descentralização e a inércia centralizadora. Nomos - Revista do Programa de Pós-Graduação em Direito - UFC, Fortaleza, v. 37, n. 1, jan./jun. 2017, p. 41.

82 De acordo com o fluxograma desenvolvido pela ANVISA e com base na RDC $n^{\circ}$ 200/2017, o registro de medicamentos novos deve percorrer as seguintes etapas: primeiramente, a regularização sanitária da empresa, com a emissão de Autorização de Funcionamento de Empresa (AFE), seguido de Licença de Funcionamento (LF) e emissão do Certificado de Boas Práticas de Funcionamento (CBPF); a segunda etapa é a identificação da petição junto à ANVISA, com a possibilidade de registro, alteração, revalidação, cancelamento e outras, seguido da identificação do Código de Assunto da Petição e verificação da documentação necessária; a terceira é o peticionamento na ANVISA; Análise da petição pela ANVISA; Ao cabo, finda-se o processo com o resultado do peticionamento, com deferimento ou indeferimento da petição publicado em DOU. In: ANVISA. Regularização de Produtos - Medicamentos. Disponível em: http://portal.anvisa.gov.br/registros-e-autorizacoes/ medicamentos/produtos/medicamentos-novos/registro. Acesso em: 7.06.2019.

83 Sobre o tema, ressalte-se tais considerações: "Es más que evidente la sujeción del Poder Público a la obligación de dar al ciudadano una respuesta expresa a sus demandas que fueran deducidas a través de un procedimiento 
demandante de forma vinculada à vontade da iniciativa privada. ${ }^{84} \mathrm{O}$ particular pode solicitar a importação de medicamento sujeito a controle especial para uso próprio com a finalidade de tratamento de saúde, ${ }^{85}$ o que não se confunde com o registro do medicamento na ANVISA. Outrossim, se há requisição de que o medicamento esteja registrado em outras agências reguladoras fora do Brasil - demonstrando que o medicamento é eficaz para o fim que pretende o demandante - a solicitação de registro na ANVISA em nada interfere na apreciação da imprescindibilidade e eficácia do medicamento, eis que é ato meramente formal para fins da ação judicial.

A solicitação de registro não demonstra a eficácia do tratamento, eis que não há garantia de que o registro será deferido pela ANVISA; ainda, não demonstra a necessidade do medicamento pelo demandante; não comprova a hipossuficiência da parte; outrossim não demonstra a existência de registro no exterior. Desse modo, por todos estes elementos, este requisito firmado pelo STF não se afigura como razoável, eis que pode inclusive colocar o direito fundamental à saúde e à vida em risco.

Diante de tais considerações, inicialmente, deve-se reconhecer que não é adequada a simples concessão imediata de autorização para o uso dos referidos medicamentos com substâncias proibidas, mas sim a defesa de um juízo de ponderação no caso concreto de modo que a tutela jurisdicional seja efetiva na garantia dos direitos fundamentais, em plena consonância com as determinações da lei. Ainda, é imperioso buscar no Direito administrativo os elementos aptos à satisfação dos direitos fundamentais sociais, eis que esta atividade é atribuída primariamente à Administração

administrativo. El art. 48 de la Ley brasileña no 9.784/99 (Ley Federal de Procedimiento Administrativo) establece que "la Administración tiene el deber de explícitamente emitir decisión en los procedimientos administrativos, solicitudes o reclamos en el marco de su competencia". El problema surge cuando ella no cumple con este deber elemental, o incluso cuando lo hace dentro de un lapso de tiempo irrazonable, lo que obliga al ciudadano a esperar meses o incluso años para recibir una respuesta dela Administración a su petición.(1) En el caso de procedimientos que implican la protección de derechos sociales, son aún más evidentes los efectos perjudiciales ocasionados por la demora del Estado en el cumplimiento de la petición hecha por vía administrativa ya que las pretensiones se refieren a la protección esencial de necesidades in-dispensables y a la promoción de la dignidad de la persona. De ahí la importancia de concebir adecuadamente el significado del concepto del "plazo razonable" y las consecuencias jurídicas provocadas por el silencio de la Administración. La Constitución de Brasil garantiza al ciudadano, en su art. $5^{\circ}, L X X-$ VIII, el derecho fundamental a la razonable duración de los procedimientos administrativos y procesos judiciales, así como a los medios que garantizan la celeridad de su tramitación." In: HACHEM, Daniel Wunder. Procedimientos administrativos reivindicatorios de derechos sociales: deber de decidir em plazo razonable vs. silencio administrativo. Estudios de Derecho Administrativo, Montevideo, n. 10, jul./dic. 2014, p. 214-215.

84 Sobre a atuação da iniciativa privada em matéria de saúde: BERTOTTI, Bárbara Mendonça; PIVETTA, Saulo Lindorfer. A integração da iniciativa privada ao sistema público de saúde brasileiro: limites e possibilidades. Revista Eurolatinoamericana de Derecho Administrativo, Santa Fe, vol. 5, n. 2, p. 239-265, jul./dic. 2018.

85 ANVISA. Importação de medicamentos sujeitos a controle especial, à base de outras substâncias, para uso próprio e para fins de tratamento de saúde. Disponível em: http://portal.anvisa.gov.br/importacao-controlados/saiba-mais. Acesso em: 15.06.2019. 
Pública (para que só posteriormente haja a atuação judicial), ${ }^{86}$ ensejando também uma regulamentação administrativa eficaz. ${ }^{87}$

De modo geral, nas demandas judiciais por remédios observa-se que pouco se escreve, decide ou reflete sobre a real condição de quem está pleiteando o tratamento. Faz-se necessário perceber que estas pessoas terão de pedir, enfrentar a falta de conhecimento de operadores do Direito sobre o assunto, tanto sobre os mecanismos de funcionamento da assistência pública de saúde, quanto em relação à doença que lhe acomete. ${ }^{88}$ Este sistema busca criar uma padronização da própria jurisprudência, com a criação de requisitos e até um engessamento dos parâmetros para o provimento judicial. Destarte, parte-se novamente da necessidade de abertura para desenvolvimento da pesquisa em relação às substâncias proscritas no âmbito nacional, a fim de demonstrar a eficácia de múltiplos tratamentos à base de tais substâncias, bem como a possibilidade de desenvolvimento de uma melhor qualidade de vida e saúde de diversos pacientes com tais tratamentos vedados pelo Direito Penal.

\section{A UTILIZAÇÃO DE FÁRMACOS COM SUBSTÂNCIAS PROIBIDAS: REGULAMENTAÇÃO E JUDICIALIZAÇÃO}

É incontestável que os problemas sociais vividos no país guardam íntima relação com a medida da prestação dos serviços públicos, sendo necessário equilíbrio no repensar da gestão destes serviços à luz da realidade de carência social experimentada pela população. ${ }^{89}$ Neste sentido, há de se considerar que a dignidade da pessoa humana é o ponto de partida para a justificação dos fins do Estado democrático contemporâneo, possuindo a felicidade como determinante imprescindível da atuação estatal para

86 HACHEM, Daniel Wunder. Tutela administrativa efetiva dos direitos fundamentais sociais: por uma implementação espontânea, integral e igualitária. Tese (Doutorado) - Universidade Federal do Paraná, Setor de Ciências Jurídicas, Programa de Pós-Graduação. Curitiba, 2014. p. 58.

87 Trata-se, sobretudo, de um dever estatal em relação ao desenvolvimento de políticas públicas aptas a proteger o direito fundamental envolto: "Um direito fundamental social (que exija prestações positivas do Estado) não demanda somente uma obrigação imediata de patrocínio Estatal, mas sim um complexo encadeamento de atos governamentais que visem a satisfação da necessidade social. São necessárias, portanto, políticas públicas de implementação. [...] Enquanto provedor máximo, o Estado deve agir de forma a conciliar os investimentos e gastos públicos, pautando-se na previsão constitucional e legal dos direitos sociais." In: DOTTA, Alexandre Godoy; CABRAL, Rodrigo Maciel. Mínimo Existencial na Hermenêutica da Jurisprudência Brasileira Referente às Políticas Públicas Relativas ao Direito à Educação. Revista de Estudos Constitucionais, Hermenêutica e Teoria do Direito. a. 10. v.2., mai./ago. 2018, p. 139/140.

88 RAYMUNDO, Giseli Valezi. A crise política de medicamentos no Brasil ..., p. 217.

89 VALLE, Vivian Cristina Lima López. Serviço Público, Desenvolvimento Econômico e a Nova Contratualização da Administração Pública: o Desafio na Satisfação dos Direitos Fundamentais. In: BACELLAR FILHO, Romeu Felipe; GABARDO, Emerson; HACHEM, Daniel Wunder (Coord.). Globalização, Direitos Fundamentais e Direito Administrativo: novas perspectivas para o desenvolvimento econômico e socioambiental. Belo Horizonte: Fórum, 2011. p. 284. 
atingir o desenvolvimento da personalidade do cidadão..$^{90}$ Portanto, busca-se atingir o pleno desenvolvimento pessoal através de prestações estatais aptas a concretizar o desenvolvimento, primariamente observando-se as necessidades e anseios sociais.

Em termos de direitos fundamentais sociais, a Constituição da República de 1988 estabeleceu em seu artigo $6^{\circ}$ um rol que abarca o direito à educação, trabalho, lazer, segurança, previdência social, proteção à maternidade e à infância, assistência aos desamparados e a saúde. Mais adiante, o texto constitucional pormenoriza o título relativo à Ordem Social (artigos 193 a 232) trazendo mecanismos e meios de ação para que o Estado forneça aos indivíduos titulares destes direitos subjetivos públicos e interesses legítimos tais direitos. ${ }^{91}$

Relativamente ao direito à saúde, o artigo 196 da Constituição da República afirma que "é direito de todos e dever do Estado, garantido mediante políticas sociais e econômicas que visem à redução do risco de doença e de outros agravos e ao acesso universal e igualitário às ações e serviços para sua promoção, proteção e recuperação." De pronto, observa-se a universalidade desse direito bem como a necessidade de uma prestação positiva estatal a fim de assegurá-lo. ${ }^{92}$ Já no artigo 200 da Constituição, direciona-se ao Sistema Único de Saúde uma série de competências funcionais, ${ }^{93}$ demonstrando a necessidade de uma prestação positiva estatal apta a concretizar o direito à saúde e proteger o direito à vida. ${ }^{94}$

90 GABARDO, Emerson. A Felicidade como Fundamento Teórico do Desenvolvimento em um Estado Social. Revista Digital de Direito Administrativo. v. 5, n. 1, 2018, p. 106.

91 TÁCITO, Caio. Constituições Brasileiras: 1988. Brasília: Senado Federal - Ministério da Ciência e Tecnologia, Centro de Estudos Estratégicos, 2005. p. 28.

92 Ressalte-se acerca da correlação entre interesse público e a elaboração de políticas públicas: "A conquista do interesse público requer a presença de medidas corretivas por meio de políticas públicas que têm absoluta correspondência com os direitos individuais (como é o caso da saúde pública)." In: GABARDO, Emerson. O princípio da supremacia do interesse público sobre o interesse privado como fundamento do Direito Administrativo Social. Revista de Investigações Constitucionais, Curitiba, v. 4, n. 2, maio/ago., 2017. p. 121-122.

93 "Art. 200. Ao sistema único de saúde compete, além de outras atribuições, nos termos da lei: I - controlar e fiscalizar procedimentos, produtos e substâncias de interesse para a saúde e participar da produção de medicamentos, equipamentos, imunobiológicos, hemoderivados e outros insumos; II - executar as ações de vigilância sanitária e epidemiológica, bem como as de saúde do trabalhador; III - ordenar a formação de recursos humanos na área de saúde; IV - participar da formulação da política e da execução das ações de saneamento básico; V - incrementar, em sua área de atuação, o desenvolvimento científico e tecnológico e a inovação; $\mathrm{VI}$ - fiscalizar e inspecionar alimentos, compreendido o controle de seu teor nutricional, bem como bebidas e águas para consumo humano; VII - participar do controle e fiscalização da produção, transporte, guarda e utilização de substâncias e produtos psicoativos, tóxicos e radioativos; VIII - colaborar na proteção do meio ambiente, nele compreendido o do trabalho."

94 Ressalte-se, em relação à garantia do direito fundamental à saúde a imprescindibilidade do tratamento adequado, com garantia de qualidade de vida na prestação. Em razão desta afirmativa, gize-se: Por sua vez, o Brasil, que adotou o modelo britânico na construção do Sistema Único de Saúde garantido na Constituição Federal de 1988, no embalo da redemocratização do país, corre o risco de retroceder na oferta dos serviços públicos de saúde em contratos de gestão com organizações sociais, cujas execuções não são devidamente fiscalizadas pelo Poder Público, possibilitando o desvio de recursos públicos, corrupção e prejuízo à qualidade do serviço, como se tem observado, em prejuízo do atendimento de saúde da população. In: BECHARA, Fábio Ramazzini; COSTA, Fernanda Soraia Pacheco. Eficiência na prestação de serviços de saúde: experiência brasileira 
A partir da interpretação sistemática dos enunciados constitucionais que tratam sobre o direito à saúde, vê-se o surgimento de um direito fundamental em sentido amplo que reúne várias prestações jurídicas jusfundamentais com diferentes funções, ${ }^{95}$ sejam elas: função de defesa, por meio da qual há liberdade de escolha de práticas diagnósticas, métodos terapêuticos e medicamentos que o titular do direito vai utilizar, vedando-se imposições estatais; função de prestação fática, pela qual deve-se fornecer serviços médicos ambulatoriais ao cidadão; função de organização, para criação de órgãos e pessoas jurídicas bem estruturados para atendimento da população; função de procedimento, pela qual o Estado deve elaborar normas administrativas para regulamentação da distribuição gratuita de medicamentos, assim como formular listas de medicamentos que integram o componente básico da assistência farmacêutica; e função de proteção, definindo-se uma política pública sanitária que fixe normas proibitivas acerca da comercialização de produtos e insumos potencialmente causadores de risco à saúde, também fiscalizando a observância de tais normas pelos particulares. ${ }^{96}$

A combinação destas funções expressas através das diversas prestações jurídicas jusfundamentais resulta em uma proteção do direito de escolha pelo indivíduo daquele tratamento que irá melhor atender às suas necessidades. ${ }^{97}$ Portanto, o texto

do modelo gerencial e comparativo com os países da common law. A\&C - Revista de Direito Administrativo \& Constitucional, Belo Horizonte, ano 19, n. 75, jan./mar. 2019, p. 78.

95 A organização destas funções não é algo fácil de ser concretizado. Entretanto, atualmente é possível que a Administração Pública se utilize de mecanismos de inteligência artificial para gerir a base de dados e buscar soluções mais eficientes para os complexos problemas desta seara. Sobre o assunto, ver: BRAVO, Álvaro Avelino Sánchez. Marco Europeo para una inteligencia artificial basada en las personas. International Journal of Digital Law, Curitiba, v. 1, n. 1, jan./abr. 2020; CORVALÁN, Juan Gustavo. Inteligencia Artificial GPT-3, Pretoria y Oráculos Algorítmicos en el Derecho. International Journal of Digital Law, Curitiba, v. 1, n. 1, jan./abr. 2020; CORVALÁN, Juan Gustavo. Administración Pública digital e inteligente: transformaciones en la era de la inteligencia artificial. Revista de Direito Econômico e Socioambiental, Curitiba, v. 8, n. 2, p. 26-66, maio/ago. 2017; FIGUEIREDO, Carla Regina Bortolaz de; CABRAL, Flávio Garcia. Inteligência artificial: machine learning na Administração Pública. International Journal of Digital Law, Curitiba, v. 1, n. 1, jan./abr. 2020; STRINGHINI, Antonella. Asistencia virtual automatizada e inclusiva para optimizar la relación de la ciudadanía con la Administración Pública. International Journal of Digital Law, Curitiba, v. 1, n. 1, jan./abr. 2020.

96 HACHEM, Daniel Wunder. Tutela administrativa efetiva dos direitos fundamentais sociais: ..., p. 33.

97 Importante distinção, neste tema, sobre "direito fundamental" e "prestações jurídicas jusfundamentais": "Se observado o direito fundamental como um todo, pode-se perceber que dele decorrem multifárias pretensões jurídicas. Ou seja: uma compreensão global do direito fundamental como a acima referida, que parte de uma norma resultante da construção hermenêutica derivada de diversas disposições constitucionais, a ele irá associar uma pluralidade de posições jurídicas subjetivas que podem ser reclamadas pelo seu titular - embora nem todas pela via individual. Logo, num sentido amplo um direito fundamental se apresenta como um conjunto de pretensões jurídicas que o ordenamento constitucional assegura aos cidadãos. Ocorre que, numa acepção estrita, cada uma dessas pretensões jurídicas isoladamente consideradas também pode ser chamada de direito fundamental. Retomando um dos exemplos antes oferecido, o direito à educação considerado como um todo (sentido amplo) engloba todas as pretensões jurídicas já mencionadas; mas a pretensão jurídica de acesso gratuito ao serviço público de educação básica, vista singularmente, não deixa de ser igualmente um direito fundamental (sentido estrito)". HACHEM, Daniel Wunder. São os direitos sociais "direitos públicos subjetivos"? Mitos e confusões na teoria dos direitos fundamentais. Revista de Estudos Constitucionais, Hermenêutica e Teoria do Direito, São Leopoldo, v. 11, n. 3, p. 404-436, set./dez. 2019. p. 426-427. 
constitucional possibilita a concretização do direito fundamental à saúde sob diversos aspectos, sempre levando em consideração as necessidades básicas extraídas da prestação jurídica pleiteada.

Em relação aos medicamentos que possuem princípios ativos ilícitos, destaque-se a importância da competência do SUS no que tange os incisos I e VII do art. 200: o controle e fiscalização de "procedimentos, produtos e substâncias de interesse para a saúde e participar da produção de medicamentos, equipamentos, imunobiológicos, hemoderivados e outros insumos", bem como "participar do controle e fiscalização da produção, transporte, guarda e utilização de substâncias e produtos psicoativos, tóxicos e radioativos". Assim, direciona-se à Administração Pública - por meio do Sistema Único de Saúde - o dever de fiscalizar e controlar a produção de medicamentos e insumos de modo geral, haja vista que a satisfação dos direitos fundamentais sociais (como é a saúde) é atribuída primariamente à Administração Pública. ${ }^{98} \mathrm{O}$ art. 196 da Constituição prevê expressamente que a saúde é um dever do Estado, em que pese os artigo 198, Il e 199 prevejam a participação da comunidade e da iniciativa privada. ${ }^{99}$

Ainda sob outra perspectiva, há de se mencionar a inércia do Poder legislativo sobre o tema, que também não atua de modo a permitir ou regulamentar a possibilidade de utilização, importação ou produção destes remédios. É facilmente demonstrável a inação legislativa diante de uma divergência de posições dos parlamentares: enquanto alguns defendem a possibilidade de liberação exclusivamente do canabidiol, outros constatam que a via legislativa deveria buscar a liberação do uso de Cannabis tanto para fins medicinais quanto recreativos. De um modo ou de outro, a regulamentação para importação do CBD foi feita pela via administrativa, não por atuação do legislativo. Entretanto, observe-se o que dispõe o artigo 23, inciso II, da Constituição da República: é competência comum da União, Estados, Distrito Federal e Municípios cuidar da saúde. ${ }^{100}$ Por sua vez, o artigo 197 da Constituição remete ao legislativo a regulamentação das ações e serviços de saúde, ${ }^{101}$ implicando em uma responsabilidade também deste Poder sobre os medicamentos a que este trabalho se refere. Primariamente, portanto, cabe ao Estado promover medidas administrativas e legislativas que assegurem o acesso à saúde e, no tocante aos medicamentos com princípios ativos proibidos, a regra não é diferente.

\footnotetext{
98 HACHEM, Daniel Wunder. Tutela administrativa efetiva dos direitos fundamentais sociais: ..., p. 58.

99 GABARDO, Emerson. Interesse Público e Subsidiariedade: o Estado e a sociedade civil para além do bem e do mal. Belo Horizonte: Fórum, 2009. p. 248.

100 "Art. 23. É competência comum da União, dos Estados, do Distrito Federal e dos Municípios: [...] II - cuidar da saúde e assistência pública, da proteção e garantia das pessoas portadoras de deficiência."

101 SARLET, Ingo Wolfgang. Direitos fundamentais em espécie. In: SARLET, Ingo Wolfgang; MARINONI, Luiz Guilherme; MITIDIERO, Daniel (Coord.). Curso de Direito Constitucional. São Paulo: Saraiva, 2015. p. 621.
} 
Sobre a atuação legislativa sobre o direito à saúde, destaque-se alguns diplomas normativos: primeiramente, a Lei Federal n 5.991/1973, que dispõe acerca do controle sanitário do comércio de drogas, medicamentos, insumos farmacêuticos e correlatos; ${ }^{102}$ por sua vez, a Lei n 6.360/1976, que ordena a vigilância sanitária a que ficam sujeitos os medicamentos, as drogas, os insumos farmacêuticos e correlatos, cosméticos, saneantes, dentre outros produtos; ${ }^{103}$ já a Lei no 8.080/90 dispõe sobre a organização e funcionamento dos serviços de proteção, promoção e recuperação da saúde. ${ }^{104}$ Diante deste cenário, demonstra-se que o Poder Legislativo - inclusive por força do texto constitucional - possui a incumbência de elaborar leis sobre o tema, pelo que poderia elaborar uma lei que disponha acercada possibilidade de produção, importação e utilização das substâncias proibidas para fins medicamentosos.

Recentemente, diante da discussão acerca da intenção de liberação do plantio de Cannabis para fins medicinais que a ANVISA pretende implementar, a Casa Civil do Palácio do Planalto emitiu nota à imprensa informando que é contrária à proposta da ANVISA, afirmando que a ideia é estimular apenas a importação da matéria prima proveniente da planta (o que, em verdade, a ANVISA já regulamentou e já autoriza, mediante procedimento administrativo). ${ }^{105}$ No entanto, este posicionamento somente atrasa o desenvolvimento de uma questão que é relevante para a saúde pública, vedando ainda a exploração econômica e científica que a pesquisa decorrente deste cenário poderia proporcionar. ${ }^{106}$ Trata-se de uma condução equivocada do assunto pelo Governo Federal, na contramão da história e de uma perspectiva racional relativa ao tema.

Em relação aos substratos proscritos, a Portaria 344/1998 exclui a possibilidade de pessoas jurídicas manipularem as substâncias proscritas em seu art. 4º, salvo com

\footnotetext{
102 "Art. $1^{\circ} \mathrm{O}$ controle sanitário do comércio de drogas, medicamentos, insumos farmacêuticos e correlatos, em todo o território nacional, rege-se por esta Lei."

103 "Art. 1 1 Ficam sujeitos às normas de vigilância sanitária instituídas por esta Lei os medicamentos, as drogas, os insumos farmacêuticos e correlatos, definidos na Lei n5.991, de 17 de dezembro de 1973, bem como os produtos de higiene, os cosméticos, perfumes, saneantes domissanitários, produtos destinados à correção estética e outros adiante definidos."

104 "Art. $1^{\circ}$ Esta lei regula, em todo o território nacional, as ações e serviços de saúde, executados isolada ou conjuntamente, em caráter permanente ou eventual, por pessoas naturais ou jurídicas de direito Público ou privado."

105 CANCIAN, Natália. Planalto é contra proposta da Anvisa de dar aval a cultivo de maconha. Disponível em: https://www1.folha.uol.com.br/equilibrioesaude/2019/06/planalto-e-contra-proposta-da-anvisa-de-dar-aval-a-cultivo-de-maconha.shtml. Acesso em: 21.06.2019.

106 Tal vedação obsta ainda o desenvolvimento sob vários aspectos. A possibilidade de empresas farmacêuticas explorarem as finalidades terapêuticas das substâncias proibidas releva-se importante do ponto de vista científico, à medida que garante-se a criação de novos tratamentos para a população; sob o viés econômico, poder-se-ia explorar o interesse do mercado em realizar tais pesquisas, incentivando a atividade econômica do ramo farmacêutico; ainda cria-se um interesse no âmbito regulatório, tendo em vista que a própria ANVISA poderia acompanhar o desenvolvimento das pesquisas e também desenvolver as suas próprias, o que facilitaria a aprovação ou rejeição de medicamentos e terapias provenientes das substâncias analisadas.
} 
autorização da ANVISA para fins científicos, ${ }^{107}$ ou seja, barra-se a produção de tais substâncias para comercialização com finalidade terapêutica no Brasil, fazendo com que a única solução seja a busca por autorização para importação e uso dessas substâncias.

Outra possível solução a ser adotada pela Administração Pública (por intermédio do Ministério da Saúde e da ANVISA) seria regulamentar de forma diferenciada a importação das substâncias proscritas apenas para fins terapêuticos, excluindo-se a liberação da droga para uso recreativo, como vem fazendo no caso do Canabidiol. Assim, garante-se o desenvolvimento da pesquisa sobre tais substâncias no plano do desenvolvimento nacional, banindo o indesejado uso indiscriminado de entorpecentes. Retomando-se a discussão acerca do tetraidrocanabinol, observa-se que a mora e a burocracia da agência responsável tornam mais difícil o acesso ao tratamento mais bem indicado para vários quadros clínicos. Tanto é possível realizar tal alteração normativa a fim de concretizar o direito subjetivo do cidadão que o Ministério Público Federal ajuizou a Ação Civil Pública nº 0090670-16.2014.4.01.3400 contra a União e a Agência Nacional de Vigilância Sanitária a fim de as rés procedessem a retirada do THC da lista F da Portaria no 344/98, para incluí-lo na lista das substâncias psicotrópicas sujeitas à notificação de receita, outrossim para que realizassem um adendo à lista E da Portaria (plantas proscritas que podem gerar substâncias entorpecentes e/ou psicotrópicas) para autorizar o uso, posse, plantio, cultura, colheita, exploração, manipulação, fabricação, distribuição, comercialização, importação, exportação e prescrição, exclusivamente para fins médicos e científicos, das diferentes espécies e variedades de cannabis, bem como dos produtos derivados dessas plantas, dentre outros pedidos que envolvem a liberação da importação dos produtos provenientes da cannabis desde que com prescrição médica. Na Ação em trâmite na $16^{a}$ Vara Federal da Subseção Judiciária do Distrito Federal foi proferido despacho que concedeu liminarmente o pedido e também houve sentença de mérito favorável (datada de 15/06/2018) confirmando a medida liminar - portanto, julgando a ação parcialmente procedente para fins de: determinar a exclusão do THC da lista F, conforme pedido do Ministério Público; adequar a lista E da Portaria com o referido adendo, autorizando o uso de tais substâncias com prescrição médica; conceder a permissão para a prescrição médica e pesquisa científica dos produtos provenientes da Cannabis. ${ }^{108}$ Igualmente, poderia a ANVISA elaborar um regime diferenciado para pesquisa e importação de medicamentos com substâncias proscritas, como o fez com

\footnotetext{
107 "Art. $4^{\circ}$ Ficam proibidas a produção, fabricação, importação, exportação, comércio e uso de substâncias e medicamentos proscritos. Parágrafo único. Excetuam-se da proibição de que trata o caput deste artigo, as atividades exercidas por Órgãos e Instituições autorizados pela Secretaria de Vigilância Sanitária do Ministério da Saúde com a estrita finalidade de desenvolver pesquisas e trabalhos médicos e científicos."

108 TRF 1. 16a Vara Federal de Brasília. Ação Civil Pública nº 0090670-16.2014.4.01.3400. Autor: Ministério Público Federal. Réus: União e Agência Nacional de Vigilância Sanitária. Ajuizamento em: 11.12.2014. Disponível em: https://processual.trf1.jus.br/consultaProcessual/processo.php?proc=00906701620 144013400\&secao=DF\&pg=1\&enviar=Pesquisar. Acesso em: 13.10.2018.
} 
o canabidiol. Assim, não se permite a importação desenfreada de substâncias ilegais e garante-se o acesso aos medicamentos necessários ao tratamento mais bem indicado.

O Ministro Luis Roberto Barroso em seu primeiro voto na Repercussão Geral no 500 reconheceu que "os avanços tecnológicos e o investimento em pesquisa permitiram o desenvolvimento de grande variedade de medicamentos, responsáveis por garantir maior bem-estar e saúde para as pessoas e por aumentar as perspectivas de cura de doenças". ${ }^{109}$ Portanto, é incoerente reconhecer os avanços que os estudos e pesquisas farmacológicos trazem, sem autorizar que tais desenvolvimentos possam ser feitos no âmbito nacional, pelo que é necessária uma regulamentação mais eficaz por parte da Administração Pública. Por outro lado, observa-se uma verdadeira deficiência na prestação do direito à saúde pela Administração: as filas e a superlotação em hospitais públicos, ${ }^{110}$ os mais de trezentos mil pedidos de medicamentos pela via judicial, ${ }^{111}$ bem como a burocracia enfrentada por famílias para conseguir importação de medicamentos na ANVISA (conforme demonstrado no documentário "Ilegal") são fenômenos aptos a comprovar a ofensa ao princípio constitucional da eficiência no que tange à garantia do direito fundamental à saúde. ${ }^{112} \mathrm{~A}$ saída para a busca de medicamentos acaba sendo a via judicial.

Importante ressaltar que "o direito ao acesso aos medicamentos é desrespeitado pelo Estado ante à insuficiência de políticas públicas proativas, preventivas e progressivas. Um desenvolvimento sustentável no que tange aos medicamentos diz respeito ao seu acesso e à fabricação". ${ }^{13}$ Assim, não se vislumbra tão somente restringir o acesso à saúde à determinação judicial em desfavor do Estado para que este forneça o medicamento pleiteado, sendo imprescindível o reconhecimento de que a tutela jurisdicional efetiva em termos de direito à saúde englobe também a autorização para uso

109 STF. Recurso Extraordinário n 657.718/MG... Disponível em: http://www.luisrobertobarroso.com.br /wp-content/uploads/2016/10/RE-657718-Medicamentos-sem-registro-Anvisa-versa\%CC\%83o-final.pdf. Acesso em: 30.09.2018.

110 O GLOBO. Filas, superlotação, faltas de funcionário e improviso: veja detalhes da crise em hospital público de Campinas. Disponível em: https://g1.globo.com/sp/campinas-regiao/noticia/filas-superlotacao-falta-de-funcionarios-e-improviso-veja-detalhes-da-crise-em-hospital-publico-de-campinas.ghtml. Acesso em: 13.10.2018.

111 OBSERVATÓRIO DE ANÁLISE POLÍTICA EM SAÚDE. Relatório de acompanhamento de políticas. Disponível em: http://www.analisepoliticaemsaude.org/oaps/matriz/analises/2/ Acesso em: 04.09.2018

112 ALVES, Letícia. Importação de remédios esbarra na burocracia. Disponível em: https://www.hojeemdia. com.br/horizontes/importa\%C3\%A7\%C3\%A3o-de-rem\%C3\%A9dio-esbarra-na-burocracia-1.313958. Acesso em: 13.10.2018. Quanto ao princípio constitucional da eficiência, ver: HACHEM, Daniel Wunder; GABARDO, Emerson. El principio constitucional de eficiencia administrativa: contenido normativo y consecuencias jurídicas de su violación. Cuestiones Constitucionales: Revista Mexicana de Derecho Constitucional, n. 39, p. 131-167, jul. /dic. 2018.

113 GLOECKNER, Joseane Ledebrum. Da necessidade de uma política pública voltada aos medicamentos para doenças raras. A\&C - Revista de Direito Administrativo \& Constitucional, Belo Horizonte, ano 15, n. 61, jul./ set. 2015. p. 256. 
de medicamentos com substratos proibidos, ou ainda cultivo de plantas medicinais. ${ }^{114}$ Deste modo, a fim de sanar uma falha no fornecimento de medicamentos por parte da Administração Pública, concretiza-se tal direito pela via judicial que começa a estabelecer certos parâmetros, como no caso da Repercussão Geral n 500 supramencionada.

Para o caso dos medicamentos com princípios ativos proibidos, há de se observar alguns fundamentos e requisitos aptos a salvaguardar o direito do titular, também como forma de não se propagar uma liberação generalizada de tais substâncias.

Primeiramente, considere-se que apesar de ser comum a referência à tutela do direito à saúde em termos gerais, cada um de seus conteúdos e prestações decorrentes desse direito pode exigir diferentes soluções jurídicas para que sejam normativamente adequadas. ${ }^{115}$ Assim, nem sempre o remédio fornecido pelo sistema único de saúde é o tratamento mais indicado ou até mesmo mais eficaz para o paciente, pelo que o uso de tratamentos alternativos provenientes de substâncias proscritas pode ser o que meIhor apresenta resultados para tratamentos diversos, conforme exposto. ${ }^{116}$ Através da concessão de autorização para importação e uso de substâncias proibidas com fins medicamentosos, objetiva-se a proteção do direito à saúde e à vida do tutelado com fundamento no conteúdo jurídico do princípio da igualdade, pelo qual "qualquer elemento residente nas coisas, pessoas ou situações, pode ser escolhido pela lei como fator discriminatório, donde se segue que, de regra, não é no traço de diferenciação escolhido que se deve buscar algum desacato ao princípio isonômico."117 Isto porque o tratamento diferenciado concedido a estes pacientes tem por fundamento uma desigualdade pré-existente em termos de saúde. Considerando-se que cada indivíduo apresenta situações próprias que demandam cuidados singulares, os quais o Direito tutela na medida

\footnotetext{
114 De modo a exemplificar a necessidade de aprofundamento do tema, observe-se que, na prática, tem sido recorrente o ajuizamento de ações buscando um modo de autorização judicial para plantio de Cannabis Sativa. Inclusive, uma das vias judiciais adotadas é a impetração de habeas corpus preventivo. O judiciário já apreciou a questão, concedendo a ordem: "Pelo exposto, CONCEDO A ORDEM DE HABEAS CORPUS, na forma do art. $660, \S 4^{\circ}$, CPP, determinando, por conseguinte, a expedição de SALVO CONDUTO em favor de TERESA CRISTINA GANDOLFI DE LIRA (CPF n 297.423.978-13), determinando que as Autoridades Policiais, eventualmente coatoras, abstenham-se de investigar, repreender, constranger ou coagir a liberdade de locomoção da impetrante-paciente em razão da importação de sementes de Cannabis Sativa bem como do plantio, extração e produção artesanal do canabidiol em favor da saúde de sua filha" (In: JFMA. Processo n 1003301-61.2019.4.01.3700. 1a Vara Federal da Seção Judiciária do Maranhão. Juiz Federal Luiz Régis Bonfim Filho. Decisão proferida em 09 de julho de 2019. Disponível em: https://www.conjur.com.br/dl/justica-maranhao-concede-uso.pdf. Acesso em: 26 de julho de 2019).

115 PIVETTA, Saulo Lindorfer. Direito fundamental à saúde: regime jurídico, políticas públicas e controle judicial. São Paulo: Revista dos Tribunais, 2014. p. 35.

116 Inclusive, sob esta óptica é que se justifica inicialmente a exigência de demonstração da imprescindibilidade do tratamento.

117 MELLO, Celso Antônio Bandeira de. O Conteúdo Jurídico do Princípio da Igualdade. São Paulo: Malheiros, 2017. p. 17.
} 
de suas necessidades, ${ }^{118}$ parte-se da isonomia como princípio que norteia as garantias diferenciadas aos pacientes que carecem do uso dessas substâncias.

Destarte, a concessão da autorização em questão fundamenta-se primariamente na análise da necessidade do portador da doença, levando em consideração as peculiaridades do caso concreto que fundamentam o pedido formulado. Tal análise deve levar em consideração o princípio da proporcionalidade (em sentido estrito), pelo qual há uma comparação entre os meios utilizados e os fins almejados pelo demandante, havendo ponderação entre elementos conflitantes; ou seja, sopesa-se o nível de restrição de um direito fundamental com o fim que se pretende com tal medida. ${ }^{119}$

Nesta seara, não se pode questionar a plausibilidade da autorização judicial sob o espectro do mínimo existencial, sob pena de restringir demasiadamente e deteriorar a garantia do direito à saúde. Como se sabe, mínimo existencial e direitos sociais não se confundem: o mínimo existencial é "um minus em relação aos direitos sociais, os quais são providos de um conteúdo mais amplo, que engloba outros deveres - não só de prestação, mas também de abstenção - que ultrapassam a circunscrição do mínimo existencial."120 Assim, a demanda por um fármaco que contém substância proibida não se encontra fora do direito fundamental, somente não compõe o mínimo existencial em matéria de direito à saúde, o que não obsta o reconhecimento do direito do demandante. Mas justamente por não integrar o mínimo existencial, a observância da necessidade do tratamento deve ser cautelosa, levando também em consideração outros tratamentos possíveis ou indicação clara de que o tratamento com a substância proscrita é o mais indicado para o quadro do cidadão. ${ }^{121}$

Se por um lado a comprovação da necessidade do fármaco é o ponto de partida para a concessão da autorização, as decisões judiciais ou administrativas devem observar a eficácia do tratamento como elemento limitador. Acertada a proposta de voto do Ministro Barroso neste posto, pois a intenção da demanda é assegurar o fornecimento de medicamento que propicie melhora ou cura da doença e seus sintomas, não podendo colocar a saúde do paciente em risco ainda maior. ${ }^{122}$ Afirma o Ministro que o

118 TAVARES, André Ramos. Curso de Direito Constitucional. São Paulo: Saraiva, 2015. p. 454.

119 PIVETTA, Saulo Lindorfer. Direito fundamental à saúde: regime jurídico, políticas públicas e controle judicial. São Paulo: Editora Revista dos Tribunais, 2014. p. 217.

120 HACHEM, Daniel Wunder. A maximização dos direitos fundamentais econômicos e sociais pela via administrativa e a promoção do desenvolvimento. Revista de Direitos Fundamentais e Democracia, v. 13, n. 13, Curitiba, UniBrasil, jan./jun. 2013, p. 360; HACHEM, Daniel Wunder. Mínimo existencial y derechos económicos y sociales: distinciones y puntos de contacto a la luz de la doctrina y jurisprudencia brasileñas. Revista Eurolatinoamericana de Derecho Administrativo, Santa Fe, vol. 1, n. 1, p. 93-138, ene./jun. 2014.

121 Sobre o assunto, ver: SARLET, Ingo Wolfgang; ZOCKUN, Carolina Zancaner. Notas sobre o mínimo existencial e sua interpretação pelo STF no âmbito do controle judicial das políticas públicas com base nos direitos sociais. Revista de Investigações Constitucionais, Curitiba, v. 3, n. 2, p. 115-141, maio/ago. 2016.

122 Importa destacar sobre o tema: "No que se refere à ausência de conhecimento técnico do Poder Judiciário em relação às doenças, ações e serviços objetos das demandas, verifica-se que há formas de solucionar a limitação com medidas técnicas colaborativas, como os Núcleos de Atendimento Técnico, cuja finalidade é 
fármaco pleiteado deve possuir registro em renomados órgãos ou agências de regulação no exterior - como a "Japanese Ministry of Health \& Welfare", do Japão, a "Food and Drug Administration" (FDA) dos Estados Unidos da América ou ainda a "European Agency for the Evaluation of Medical Products" (EMEA), da União Europeia - pois "a aprovação da droga (ainda não registrada no Brasil) em países que possuem sistemas de vigilância sanitária sérios e respeitados fora do país mitiga os riscos à saúde envolvidos no seu fornecimento a pacientes por determinação judicial". ${ }^{123}$ Assim, a existência de registro em agências internacionais aproxima o posicionamento pelo qual o Poder Judiciário pode permitir o fornecimento do fármaco, pois por algum órgão sanitário competente a fórmula foi testada e aprovada, garantindo-se a eliminação de riscos por meio da eficácia do tratamento. ${ }^{124}$ Por não propiciarem a certeza do tratamento, as medicações experimentais são excluídas da concessão pela via judicial, ainda mais em relação às substâncias proscritas que dependem de dosagem correta e podem causar dependências químicas e efeitos indesejados.

Portanto, o controle judicial para conceder a autorização para importação e uso de fármacos que possuem substâncias proscritas devem observar essencialmente dois requisitos: o primeiro é a necessidade do tratamento através de indicação médica que exclua a possibilidade de utilização de outros fármacos ou que, apesar da existência de outros tratamentos indique aquele como sendo o mais eficaz para o paciente; o segundo é a comprovação da eficácia do tratamento pleiteado através de estudos científicos e registro em outras agências sanitárias internacionais, salvaguardando a tutela do direito à saúde em um patamar seguro de atuação judicial. Assim, a partir de uma interpretação que realmente analisa as características do caso concreto proporciona-se uma prestação estatal eficaz, por meio da qual há uma descriminalização da conduta (prevista no art. 33 da Lei no 11.343/2006) por ato interpretativo do juiz, ${ }^{125}$ relativizando-se a proibição criminal em prol da proteção do direito fundamental à saúde. ${ }^{126}$

fornecer aos juízes as informações técnicas na área do direito à saúde e proporcionar maior qualidade, conhecimento e segurança sobre aspectos médicos e farmacêuticos nas demandas de saúde, em especial por ocasião de pedidos de tutela antecipada ou liminares." In: DAL POZZO, Emerson Luís; MION, Ronaldo de Paula. Controle jurisdicional das políticas públicas de saúde através da inclusão de medicamentos na relação de medicamentos essenciais do Sistema Único de Saúde. A\&C - Revista de Direito Administrativo \& Constitucional, Belo Horizonte, ano 19, n. 77, p. 199-228, jul./set. 2019. p. 216.

123 STF. Recurso Extraordinário n 657.718/MG. Relator: Ministro Marco Aurélio. DJE 12.03.2012. Disponível em: http://www.luisrobertobarroso.com.br/wp-content/uploads/2016/10/RE-657718-Medicamentos-sem-registro-Anvisa-versa \%CC\%83o-final.pdf. Acesso em: 30.09.2018;

124 RAYMUNDO, Giseli Valezi. A crise política de medicamentos no Brasil. Curitiba: Prismas, 2017. p. 196.

125 "Art. 33.Importar, exportar, remeter, preparar, produzir, fabricar, adquirir, vender, expor à venda, oferecer, ter em depósito, transportar, trazer consigo, guardar, prescrever, ministrar, entregar a consumo ou fornecer drogas, ainda que gratuitamente, sem autorização ou em desacordo com determinação legal ou regulamentar $[. . .]^{\prime \prime}$

126 Neste sentido, gize-se: "A descriminalização por ato interpretativo do juiz aproxima a prática judicial ao segundo pressuposto elencado por Baratta na visualização concreta de Política Criminal alternativa. O juiz, 
Assim como as decisões judiciais vêm compreendendo pela possibilidade de importar medicamentos sem registro na ANVISA, ${ }^{127}$ há de se propagar o desfazimento do preconceito em relação às substâncias proscritas, tutelando seu uso para proporcionar o melhor tratamento terapêutico possível. Sabe-se o quanto é difícil a posição entre uma postura mais deferente e uma mais ativa do Poder Judiciário. Neste caso ora estudado, entretanto, parecem existir motivos suficientes para a adoção da segunda alternativa, ainda que se tenha ciência dos riscos que ela carrega em si.

\section{CONCLUSÕES}

Com o objetivo de buscar o desenvolvimento de novos tratamentos, faz-se necessária uma releitura do sistema atual de combate às drogas. Não se pode ignorar o fato de que tais substâncias terminantemente proibidas pela Portaria no 344/98 do Ministério da Saúde possuem outras utilizações que não a finalidade recreativa. Neste sentido, o atual sistema de combate às drogas demonstra-se em dissonância com a realidade sobre tais substâncias, pelo que há de se enfrentar o fato de que a intolerância propaga um atraso no desenvolvimento de novos tratamentos terapêuticos, muitas vezes obstando o acesso à saúde para os que dependem de tais medicamentos - este é um caminho oposto ao proposto pelo modelo de Estado social previsto na Constituição.

O histórico do desenvolvimento da ciência neste campo muito acrescenta à discussão: desde Freud e Köller, na descoberta da anestesia local à base de cocaína, ${ }^{128}$ até a utilização e registro de medicamentos com derivados de Cannabis, os novos tratamentos surgem como alternativa aos métodos tradicionais, sendo plenamente aptos à cura ou amenização de sintomas de várias doenças. ${ }^{129}$ Não se pode ignorar tais avanços significativos em prol de uma política criminal intolerante. Neste sentido, busca-se no ordenamento a análise da possibilidade de obter autorização para importação e uso de fármacos que possuem como princípio ativo substâncias proscritas da Lista F da Portaria 344/1998.

\footnotetext{
ao interpretar, crítica e criativamente, a norma ao caso concreto (uso alternativo do direito), exclui a sanção a partir de algumas falhas no interior do direito positivo instituído (lacunas, ambiguidades e contradições) ou de possibilidades aceitas pela Dogmática mas pouco utilizadas no labor cotidiano - causas supralegais de exclusão de tipicidade (princípio da insignificância e adequação social), antijuridicidade (consentimento do ofendido) e culpabilidade." In: DE CARVALHO, Salo. A Política Criminal de Drogas no Brasil. Rio de Janeiro: Luam, 1996. p. 196-197.

127 PANORAMA FARMACÊUTICO. Justiça autoriza importação de remédios sem certificado da Anvisa. Disponível em: https://panoramafarmaceutico.com.br/2018/03/20/justica-autoriza-governo-a-importar-remedios- sem-certificado-da-anvisa/. Acesso em: 14.10.2018.

128 REIS JUNIOR, Almiro dos. Ibidem. p. 245.

129 GAUCHAZH. Conheça os remédios que contam com substâncias advindas da maconha. Disponível em: https://gauchazh.clicrbs.com.br/saude/vida/noticia/2014/05/Conheca-os-remedios-que-contam-com-substancias-advindas-da-maconha-4503256.html. Acesso em: 12.10.2018.
} 
Num primeiro momento, observa-se a incumbência dada ao Poder Legislativo de criar leis que disponham sobre as ações e serviços de saúde, por força do art. 197 da Constituição da República. Entretanto, não há qualquer texto legal que verse sobre a possibilidade de utilização de medicamentos que contenham substâncias proibidas. Assim, tendo em vista que o texto constitucional direciona o dever de garantir o direito fundamental à saúde para a Administração Pública, ${ }^{130}$ vislumbra-se a possibilidade de elaborar uma regulamentação administrativa mais eficaz, que permita o desenvolvimento científico e a importação devidamente fiscalizada destes medicamentos. ${ }^{131}$ Assim, dar-se-ia um regime diferenciado em relação a estas substâncias, permitindo seu uso para fins medicinais (com prescrição e dosagem correta), sem liberá-las para todos os fins (inclusive recreativo).

A sentença judicial que promoveu a exclusão do tetraidrocanabinol da Lista F da Portaria 344/98 determinou também a inclusão de um adendo na lista E desta Portaria, para permitir o uso da Cannabis exclusivamente para fins medicinais. ${ }^{132}$ Em que pese a determinação judicial referir-se à lista $E$, vê-se que é possível estabelecer a autorização somente em relação aos tratamentos terapêuticos, assim consagrando a proteção da saúde.

No âmbito de regulação administrativa, há de se ressaltar que já é possível observar atuação mais incisiva da ANVISA na tentativa de trazer uma regulamentação eficiente para o uso de substâncias proibidas, o que, por outro lado, tem gerado embate direto com o posicionamento do Planalto, cujo teor revela resistência ao desenvolvimento do tema. Entretanto, o assunto avança no âmbito administrativo, ressaltando-se a aprovação da Resolução de Diretoria Colegiada n 325 da ANVISA, cujo teor revisitou as substâncias anteriormente proibidas pela Lista F da Portaria n 344/1998, passando a permitir a comercialização em território nacional de medicamentos que possuem como base a Cannabis Sativa. Ainda que se trate de um avanço relevante para o tema, há de se ressaltar que não há uma regulação específica e consolidada sobre o uso de medicamentos com princípios ativos proibidos, tratando-se apenas de uma revisão daqueles que eram considerados proibidos pela Lista F da Portaria n³44/1998. Desse

130 GABARDO, Emerson. Interesse Público e Subsidiariedade: o Estado e a sociedade civil para além do bem e do mal. Belo Horizonte: Fórum, 2009. p. 248.

131 Sobre o tema, gize-se a importância de articulações entre o Estado e a sociedade a fim de otimizar as ações na garantia de justiça política: "As práticas da justiça política devem buscar a articulação entre grupos ou organizações das sociedades com esferas administrativas estatais para uma atuação que permita a otimização de ações. Para que isto ocorra são indispensáveis iniciativas formadoras que construam novas formas de conceber a atuação conjunta desses segmentos." In: GUSTIN, Miracy Barbosa de Sousa. Justiça Política: conceito a partir de olhares sobre a exclusão e o risco social. Revista Brasileira de Estudos Políticos, Belo Horizonte, n. 114, jan./jun. 2017, p. 419.

132 TRF 1. 16 ${ }^{a}$ Vara Federal de Brasília. Ação Civil Pública no 0090670-16.2014.4.01.3400. Autor: Ministério Público Federal. Réus: União e Agência Nacional de Vigilância Sanitária. Ajuizamento em: 11.12.2014. Disponível em: https://processual.trf1.jus.br/consultaProcessual/processo.php?proc $=00906701620144013400 \&$ secao=DF\&pg=1\&enviar=Pesquisar. Acesso em: 13.10.2018. 
modo, o ordenamento jurídico brasileiro carece ainda de uma regulamentação administrativa mais eficiente, a fim de salvaguardar o desenvolvimento do direito à saúde, assim como das pesquisas que envolvem tais substâncias.

Por outro lado, quando a lei é omissa ou o papel da Administração Pública resta total ou parcialmente descumprido, torna-se importante a possibilidade de ser buscada autorização judicial. ${ }^{133}$ Assim, há de se observar as necessidades do paciente portador da doença, considerando-se a tutela diferenciada para cada caso eis que cada indivíduo apresenta situações particulares. ${ }^{134}$ Neste sentido, há de se ressaltar que "a lei não deve ser fonte de privilégios ou perseguições, mas instrumento regulador da vida social que necessita tratar equitativamente todos os cidadãos".135 Partindo-se de uma desigualdade em termos de saúde e vida, ${ }^{136}$ a concessão de autorização para importação e uso de substâncias proscritas deve atender aos critérios de comprovação da necessidade do tratamento (através de exames e laudos médicos que indiquem o tratamento como mais eficaz para o quadro do paciente), bem como observar a constatação de eficácia do tratamento, que se dá através de pesquisas e registro do medicamento em outros órgãos sanitários fora do país. Ressalte-se que a necessidade e a eficácia do tratamento devem ser observadas tanto pela via administrativa quanto pela via judicial, salvaguardando a concessão de medicamento que de fato propicie melhora da vitalidade do paciente. Não se pretende incitar aleatoriamente o uso de substâncias proscritas, mas sim defender a criação de um conjunto normativo apto a garantir o acesso destas substâncias a pacientes que delas dependem, concretizando o direito fundamental à saúde sob um espectro não tradicional, inclusive, se necessário, modificando a anterior lógica de configuração institucional do Estado brasileiro. ${ }^{137}$

\footnotetext{
133 Há autores, ainda, que defendem uma atuação conjunta dos Poderes mediante a realização de "diálogos institucionais" - o que é um assunto polêmico. Nesse sentido, ver: AVILA, Ana Paula Oliveira; MELO, Karen Cristina Correa de. Separação de poderes e diálogos institucionais nos litígios envolvendo o direito à saúde. Revista de Investigações Constitucionais, Curitiba, v. 5, n. 1, p. 83-108, jan./abr. 2018.

134 TAVARES, André Ramos. Curso de Direito Constitucional. São Paulo: Saraiva, 2015. p. 454.

135 MELLO, Celso Antônio Bandeira de. O Conteúdo Jurídico do Princípio da Igualdade. São Paulo: Malheiros, 2017. p. 10.

136 Mencione-se: "O indivíduo doente ou acometido por alguma capacidade vê o seu leque de oportunidades ser reduzido, de forma que, mesmo tendo o mesmo índice de bens primários, fica em situação de desigualdade com relação a outro indivíduo saudável.." In: SILVA, Delmo da; RAMOS, Edith; DINIZ, Isadora. O Direito à saúde no âmbito da justiça como equidade: limites e possibilidades da justiça social na extensão dos direitos sociais em Rawls. Revista Brasileira de Estudos Políticos, Belo Horizonte, n. 115, jul./dez/ 2017, p. 197.

137 Como, aliás, já vem ocorrendo na área da promoção da saúde como um todo. Sobre o assunto, ver: RIBEIRO, Leandro Molhano; HARTMANN, Ivan Alberto. Judicialization of the right to health and institutional changes in Brazil. Revista de Investigações Constitucionais, Curitiba, v. 3, n. 3, p. 35-52, set./dez. 2016.
} 


\section{REFERÊNCIAS}

AGU. Judicialização da saúde no Brasil: Principais Projetos Desenvolvidos pela Coordenação de Assuntos Judiciais. Disponível em: http://portalarquivos2.saude.gov.br/images/pdf/2017/ maio/17/JUDICIALIZACAO\%20DA\%20SAUDE\%20NO\%20BRASIL\%20Principais\%20Projetos\%20 Desenvolvidos\%20pela\%20Coordenacao\%20de\%20Assuntos\%20Judiciais.pdf Acesso em: 10.09.2018;

AGU. Manifestação Jurídica Referencial sobre o medicamento Lomitapida. Disponível em: http://portalarquivos2.saude.gov.br/images/pdf/2017/maio/31/0001-2017lomitapida.pdf. Acesso em: 12.09 .2018

ALAGOAS 24 HORAS. Remédio à base de maconha ajuda no tratamento de doenças neurológicas. Disponível em: http://www.alagoas24horas.com.br/1147351/remedio-base-de-maconha-ajuda-tratamento-de-doencas-neurologicas/. Acesso em: 12.10.2018.

ALVES, Letícia. Importação de remédios esbarra na burocracia. Disponível em: https://www. hojeemdia.com.br/horizontes/importa\%C3\%A7\%C3\%A3o-derem\%C3\%A9dio-esbarra-na-burocracia-1.313958. Acesso em: 13.10.2018.

ANVISA. Orientações sobre importação de canabidiol. Disponível em: http://portal.anvisa.gov. br/importacao -de-canabidiol. Acesso em: 12.10.2018

ANVISA. Registrado primeiro medicamento à base de Cannabis Sativa. Disponível em: http:// portal.anvisa.gov.br/noticias/-/asset_publisher/FXrpx9qY7FbU/content/agencia-aprova-primeiro-remedio-a-base-de-cannabis-sativa/219201. Acesso em: 02.06.2018.

ANVISA. Importação de medicamentos sujeitos a controle especial, à base de outras substâncias, para uso próprio e para fins de tratamento de saúde. Disponível em: http://portal. anvisa.gov.br/importacao-controlados/saiba-mais. Acesso em: 15.06.2019.

ARAÚJO, Tarso. Agora é Oficial: ANVISA vai liberar a prescrição de CBD. Disponível em: https:// super.abril.com.br/blog/psicoativo/agora-e-oficial-anvisa-vai-liberar-a-prescricao-de-cbd/. Acesso em: 12.10.2018.

AQTIC. Indications and Usage. Disponível em: http://www.actiq.com/. Acesso em: 12.10.2018.

ASSOCIAÇÃO BRASILEIRA DE PACIENTES DE CANNABIS MEDICINAL - AMA+ME. Conheça a história da Cannabis Medicinal. Disponível em: https://amame.org.br/historia-da-cannabis-medicinal/. Acesso em: 29.09.2018.

ASSOCIAÇÃO BRASILEIRA DE PACIENTES DE CANNABIS MEDICINAL - AMA+ME. Suporte à quimioterapia potencial terapêutico. Disponível em: https://amame.org.br/cannabis/suporte-a-quimioterapia/. Acesso em: 12.10.2018. 
AVILA, Ana Paula Oliveira; MELO, Karen Cristina Correa de. Separação de poderes e diálogos institucionais nos litígios envolvendo o direito à saúde. Revista de Investigações Constitucionais, Curitiba, v. 5, n. 1, p. 83-108, jan./abr. 2018.

BARROS, Daniel Martins de. A liberação do Canabidiol. Disponível em: https://emais.estadao. com.br/blogs/daniel-martins-de-barros/a-liberacao-do-canabidiol/. Acesso em: 10.09.2018.

BECHARA, Fábio Ramazzini; COSTA, Fernanda Soraia Pacheco. Eficiência na prestação de serviços de saúde: experiência brasileira do modelo gerencial e comparativo com os países da common law. A\&C - Revista de Direito Administrativo \& Constitucional, Belo Horizonte, ano 19, n. 75, p. 65-82, jan./mar. 2019.

BERTOTTI, Bárbara Mendonça; PIVETTA, Saulo Lindorfer. A integração da iniciativa privada ao sistema público de saúde brasileiro: limites e possibilidades. Revista Eurolatinoamericana de Derecho Administrativo, Santa Fe, vol. 5, n. 2, p. 239-265, jul./dic. 2018.

BRAVO, Álvaro Avelino Sánchez. Marco Europeo para una inteligencia artificial basada en las personas. International Journal of Digital Law, Curitiba, v. 1, n. 1, jan./abr. 2020.

BRASIL. Ministério da Saúde. Secretaria de Ciência, Tecnologia e Insumos Estratégicos. Departamento de Assistência Farmacêutica e Insumos Estratégicos. Relação Nacional de Medicamentos Essenciais: RENAME 2018. Ministério da Saúde, Secretaria de Ciência, Tecnologia e Insumos Estratégicos, Departamento de Assistência Farmacêutica e Insumos Estratégicos. - Brasília: Ministério da Saúde, 2018. Disponível em: https://www.conass.org.br/wp-content/uploads/2018/11/RENAME-2018.pdf. Acesso em: 8.06.2019.

CALZOLARI. Izabella. Anvisa decide retirar o canabidiol da lista de substâncias de uso proibido. Disponível em: http://g1.globo.com/bemestar/noticia/2015/01/ anvisa-decide-retirar-o-canabidiol-da-lista-de-substancias-de-uso-proibido.html. Acesso em: 12.10.2018.

CANCIAN, Natália. Planalto é contra proposta da Anvisa de dar aval a cultivo de maconha. Disponível em: https://www1.folha.uol.com.br/equilibrioesaude/2019/06/planalto-e-contra-proposta-da-anvisa-de-dar-aval-a-cultivo-de-maconha.shtml. Acesso em: 21.06.2019.

CARVALHO, Salo de. A Política Criminal de Drogas no Brasil. Rio de Janeiro: Luam, 1996.

CATARSE. Repense: campanha de conscientização sobre a maconha medicinal. Disponível em: https://www.catarse.me/repense. Acesso em: 12.10.2018.

CHADE, Jamil. Orçamento para saúde no Brasil fica abaixo da média mundial, diz OMS. Disponível em: https://saude.estadao.com.br/noticias/geral,orcamento-para-saude-no-brasil-fica-abaixo-da-media-mundial,70001788024. Acesso em: 28.09.2018

CENPRE. Histórico da Maconha. Disponível em: http://www.cenpre.furg.br/drogas?id=62. Acesso em: 29.09.2018. 
CORVALÁN, Juan Gustavo. Administración Pública digital e inteligente: transformaciones en la era de la inteligencia artificial. Revista de Direito Econômico e Socioambiental, Curitiba, v. 8, n. 2, p. 26-66, maio/ago. 2017.

CORVALÁN, Juan Gustavo. Inteligencia Artificial GPT-3, Pretoria y Oráculos Algorítmicos en el Derecho. International Journal of Digital Law, Curitiba, v. 1, n. 1, jan./abr. 2020.

DAL POZZO, Emerson Luís; MION, Ronaldo de Paula. Controle jurisdicional das políticas públicas de saúde através da inclusão de medicamentos na relação de medicamentos essenciais do Sistema Único de Saúde. A\&C - Revista de Direito Administrativo \& Constitucional, Belo Horizonte, ano 19, n. 77, p. 199-228, jul./set. 2019.

DENARC. Ópio. Disponível em: http://www.denarc.pr.gov.br/modules/conteudo/ conteudo.php?conteudo=25. Acesso em: 29.09.2018.

DEZAN, Sandro Lucio; BRASIL JÚNIOR, Samuel Meira. A juridicidade do Estado-administração na concretização de políticas públicas de saúde - Um método para a justificação da eficácia horizontal dos direitos fundamentais. A\&C - Revista de Direito Administrativo \& Constitucional, Belo Horizonte, ano 16, n. 63, p. 211-238, jan./mar. 2016.

DUARTE, Danilo Freire. Uma breve história do ópio e dos opióides. Revista Brasileira de Anestesiologia. v. 55, n. 1, jan./fev., 2005. p. 135-146.

DOTTA, Alexandre Godoy; CABRAL, Rodrigo Maciel. Mínimo Existencial na Hermenêutica da Jurisprudência Brasileira Referente às Políticas Públicas Relativas ao Direito à Educação. Revista de Estudos Constitucionais, Hermenêutica e Teoria do Direito. a. 10. v.2., mai./ago. 2018, p. 138-149.

EL PAÍS. EUA autorizam o primeiro medicamento feito a partir de maconha. Disponível em: https://brasil.elpais.com/brasil/2018/06/25/actualidad/1529952375_014000.html. Acesso em: 30.09.2018.

ESCLEROSE MÚLTIPLA. Uso de derivados da Cannabis na Esclerose Múltipla. Disponível em: http://esclerosemultipla.com.br/2015/06/24/uso-de-derivados-da-cannabis-na-esclerose-multipla/. Acesso em: 12.10.2018.

EXAME. Anvisa regulamenta medicamentos à base de maconha, mas rejeita cultivo. Disponível em: https://exame.abril.com.br/brasil/anvisa-aprova-regulamentacao-de-medicamentos-a-base-de-maconha/. Acesso em: 06.12.2019.

FIGUEIREDO, Carla Regina Bortolaz de; CABRAL, Flávio Garcia. Inteligência artificial: machine learning na Administração Pública. International Journal of Digital Law, Curitiba, v. 1, n. 1, jan./ abr. 2020.

FRANÇA, Valenio Pérez. O namoro de Freud e a descoberta da anestesia tópica. Revista Médica de Minas Gerais. v. 20, n. 1, jan./mar. 2010. p. 131-137. 
FREITAS, Daniel Castanha de. Direito fundamental à saúde e medicamentos de alto custo. Belo Horizonte: Fórum, 2018.

GABARDO, Emerson. A Felicidade como Fundamento Teórico do Desenvolvimento em um Estado Social. Revista Digital de Direito Administrativo. V. 5, n. 1, 2018. p. 99-141.

GABARDO, Emerson. O princípio da supremacia do interesse público sobre o interesse privado como fundamento do Direito Administrativo Social. Revista de Investigações Constitucionais, Curitiba, v. 4, n. 2, p. 95-130, maio/ago. 2017.

GABARDO, Emerson. Interesse Público e Subsidiariedade: o Estado e a sociedade civil para além do bem e do mal. Belo Horizonte: Fórum, 2009.

GAUCHAZH. Conheça os remédios que contam com substâncias advindas da maconha. Disponível em: https://gauchazh.clicrbs.com.br/saude/vida/noticia/ 2014/05/Conheca-os-remedios-que-contam-com-substancias-advindas-da-maconha-4503256.html. Acesso em: 12.10.2018.

GIMENEZ, Charlise de Paula Colet; DEL'OLMO, Florisbal de Souza; ANGELIN, Rosângela. Dos Direitos Humanos e dos Conflitos na Sociedade Líquida pós-moderna. Nomos - Revista do Programa de pós-graduação da UFC, Fortaleza, v. 37.2, p. 259-279, jul./dez. 2017.

GLOECKNER, Joseane Ledebrum. Da necessidade de uma política pública voltada aos medicamentos para doenças raras. A\&C - Revista de Direito Administrativo \& Constitucional, Belo Horizonte, ano 15, n. 61, p. 233-262, jul./set., 2015.

GRILLO, Breno. Marco Aurélio complementa voto em julgamento sobre fornecimento de remédios. Disponível em: https:/www.conjur.com.br/2016-set-28/pedido-vista-suspende-julgamento-obrigacao-fornecer-remedio Acesso em: 18.09.2018.

GUSTIN, Miracy Barbosa de Sousa. Justiça Política: conceito a partir de olhares sobre a exclusão e o risco social. Revista Brasileira de Estudos Políticos, Belo Horizonte, n. 114, p. 409-423, jan./ jun. 2017.

HACHEM, Daniel Wunder. A maximização dos direitos fundamentais econômicos e sociais pela via administrativa e a promoção do desenvolvimento. Revista de Direitos Fundamentais e Democracia, v. 13, n. 13, Curitiba, UniBrasil, jan./jun. 2013. p. 340-399.

HACHEM, Daniel Wunder. Mínimo existencial y derechos económicos y sociales: distinciones y puntos de contacto a la luz de la doctrina y jurisprudencia brasileñas. Revista Eurolatinoamericana de Derecho Administrativo, Santa Fe, vol. 1, n. 1, p. 93-138, ene./jun. 2014.

HACHEM, Daniel Wunder. Procedimientos administrativos reivindicatorios de derechos sociales: deber de decidir em plazo razonable vs. silencioadministrativo. Estudios de Derecho Administrativo, Montevideo, n. 10, jul./dic., 2014. p. 213-251. 
HACHEM, Daniel Wunder. São os direitos sociais "direitos públicos subjetivos"? Mitos e confusões na teoria dos direitos fundamentais. Revista de Estudos Constitucionais, Hermenêutica e Teoria do Direito, São Leopoldo, v. 11, n. 3, p. 404-436, set./dez. 2019.

HACHEM, Daniel Wunder. Tutela administrativa efetiva dos direitos fundamentais sociais: por uma implementação espontânea, integral e igualitária. Tese (Doutorado) - Universidade Federal do Paraná, Setor de Ciências Jurídicas, Programa de Pós-Graduação. Curitiba, 2014.

HACHEM, Daniel Wunder; GABARDO, Emerson. El principio constitucional de eficiencia administrativa: contenido normativo y consecuencias jurídicas de su violación. Cuestiones Constitucionales: Revista Mexicana de Derecho Constitucional, n. 39, p. 131-167, jul. /dic. 2018.

ÍNDICE. Etretinato. Disponível em: https://www.indice.eu/pt/medicamentos/DCl/ etretinato/informacao-geral. Acesso em: 12.10.2018.

JFMA. Processo no 1003301-61.2019.4.01.3700. 1a Vara Federal da Seção Judiciária do Maranhão. Juiz Federal Luiz Régis Bonfim Filho. Decisão proferida em 09 de julho de 2019. Disponível em: https://www.conjur.com.br/dl/justica-maranhao-concede-uso.pdf. Acesso em: 26.07.2019.

LIMA, Edilberto Pontes. O STF e o equilíbrio federativo: entre a descentralização e a inércia centralizadora. Nomos - Revista do Programa de Pós-Graduação em Direito - UFC, Fortaleza, v. 37 , n. 1, p. 35-50 jan./jun. 2017.

LOPES, Antônio Carlos (Ed.). Diagnóstico e tratamento. v. 2. Barueri: Manole, 2006.

MARIANO, Cynara Monteiro. Emenda constitucional 95/2016 e o teto dos gastos públicos: Brasil de volta ao estado de exceção econômico e ao capitalismo do desastre. Revista de Investigações Constitucionais, Curitiba, v. 4, n. 1, p. 259-281, jan./abr. 2017.

MELLO, Celso Antônio Bandeira de. O Conteúdo Jurídico do Princípio da Igualdade. São Paulo: Malheiros, 2017.

MUNIZ, Mariana. Morre autora de ação no STF sobre fornecimento de remédio sem registro na Anvisa. Disponível em: https://www.jota.info/dados/rui/morre-autora-de-acao-no-stf-sobre-fornecimento-de-remedio- sem-registro-na-anvisa-19062018 Acesso em: 17.09.2018.

O GLOBO. Filas, superlotação, faltas de funcionário e improviso: veja detalhes da crise em hospital público de Campinas. Disponível em: https://g1.globo.com/sp/campinas-regiao/noticia/filas-superlotacao-falta-de-funcionarios-e-improviso-veja-detalhes-da-crise-em-hospital-publico-de-campinas.ghtml. Acesso em: 13.10.2018.

OBSERVATÓRIO DE ANÁLISE POLÍTICA EM SAÚDE. Relatório de acompanhamento de políticas. Disponível em http://www.analisepoliticaem saude.org/oaps/matriz/analises/2/. Acesso em: 04.09.2018. 
O'HARE, Ryan. Magic mushrooms may'reset' the brains of depressed patients. Imperial College of Science, Technology and Medicine. Disponível em: https://www.imperial.ac.uk/news/182410/ magic-mushrooms-reset-brains-depressed-patients/. Acesso em: 8.06.2019.

OMS. Dados estatísticos sobre o Brasil. Disponível em: http://www.who.int/countries/bra/es/. Acesso em: 28.09.2018.

ONCOGUIA. Medicamentos analgésicos Opioides. Disponível em: http://www. oncoguia.org. br/conteudo/analgesicos-opioides/7674/902/. Acesso em: 29.09.2018.

PANORAMA FARMACÊUTICO. Justiça autoriza importação de remédios sem certificado da Anvisa. Disponível em: https://panoramafarmaceutico.com.br/ 2018/03/20/justica-autoriza-governo-a-importar-remedios- sem-certificado-da-anvisa/. Acesso em: 14.10.2018.

PAIVA, Leonardo Lindroth de; LEINDORF, Cecilia de Aguilar. O usuário do serviço Público como consumidor: visões do direito administrativo e do consumidor e sua atual aplicação. In: BETTES, Janaína Maria; DE PAIVA, Leonardo Lindroth; Lucimara Deretti (Coord.). Temas de Desenvolvimento e Socioambientalismo. Curitiba: CRV, 2016.

PIVETTA, Saulo Lindorfer. Direito fundamental à saúde: regime jurídico, políticas públicas e controle judicial. São Paulo: Revista dos Tribunais, 2014.

PORTAL DA TRANSPARÊNCIA. Detalhamento dos gastos por meio de cartão de pagamento. Disponível em: http://www.portaltransparencia.gov.br/cartoes/consulta? ordenarPor=valorTotal\&dir ecao=desc. Acesso em: 20.05.2019.

RAYMUNDO, Giseli Valezi. A crise política de medicamentos no Brasil. Curitiba: Prismas, 2017.

REIS JUNIOR, Almiro dos. Sigmund Freud (1856-1939) e Karl Köller (1857-1944) e a Descoberta da Anestesia Local. Revista Brasileira de Anestesiologia. v. 59, n. 2, mar./abr., 2009. p. 244-257.

RIBEIRO, Leandro Molhano; HARTMANN, Ivan Alberto. Judicialization of the right to health and institutional changes in Brazil. Revista de Investigações Constitucionais, Curitiba, v. 3, n. 3, p. 35-52, set./dez. 2016.

SARLET, Ingo Wolfgang; MARINONI, Luiz Guilherme; MITIDIERO, Daniel (Coord.). Curso de Direito Constitucional. São Paulo: Saraiva, 2015.

SARLET, Ingo Wolfgang; ZOCKUN, Carolina Zancaner. Notas sobre o mínimo existencial e sua interpretação pelo STF no âmbito do controle judicial das políticas públicas com base nos direitos sociais. Revista de Investigações Constitucionais, Curitiba, v. 3, n. 2, p. 115-141, maio/ago. 2016.

SALGADO, Eneida Desiree. Populismo judicial, moralismo e o desprezo à Constituição: a democracia entre velhos e novos inimigos. Revista Brasileira de Estudos Políticos, Belo Horizonte, n. 117, p. 193-217, jul./dez. 2018. 
SCHIER, Paulo Ricardo. Constitucionalização no contexto da Constituição de 1988. In: CLÈVE, Clèmerson Merlin (Org.). Direito Constitucional Brasileiro. v. 1. São Paulo: Revista dos Tribunais, 2014, p. 43-60.

SENADO FEDERAL. Neurocientista aponta propriedades medicinais da maconha. Disponível em: https://www12.senado.leg.br/noticias/materias/2014/08/25/neurocientista-aponta-propriedades-medicinais-da-maconha. Acesso em: 29.09.2018.

SILVA, Delmo da; RAMOS, Edith; DINIZ, Isadora. O Direito à saúde no âmbito da justiça como equidade: limites e possibilidades da justiça social na extensão dos direitos sociais em Rawls. Revista Brasileira de Estudos Políticos, Belo Horizonte, n. 115, p. 169-201, jul./dez/ 2017.

STJ. Recurso Especial no 1.657.156/RJ. Rel. Ministro Benedito Gonçalves, julgado em 25/04/2018, DJe 04/05/2018.

STF. Recurso Extraordinário n 657.718/MG. Relator: Ministro Marco Aurélio. DJE 12.03.2012. Disponível em: http://www.luisrobertobarroso.com.br/wp-content/uploads/2016/10/RE-657718-Medicamentos-sem-registro-Anvisa-versa \%CC\%83o-final.pdf. Acesso em: 30.09.2018.

STF. Tema de Repercussão Geral no 6 - RE 566471. Relator Min. Marco Aurélio. Disponível em: http://www.stf.jus.br/portal/jurisprudenciaRepercussao/verAndamentoProcesso.asp? incidente $=2565078 \&$ numeroProcesso $=566471 \&$ classeProcesso $=$ RE\&numeroTema $=6$. Acesso em: 20.05.2019.

STRAPAZZON, Carlos Luiz. Direitos constitucionais de seguridade social no Brasil: uma abordagem orientada por direitos humanos. A\&C - Revista de Direito Administrativo \& Constitucional, Belo Horizonte, ano 17, n. 67, p. 185-215, jan./ mar. 2017.

STRINGHINI, Antonella. Asistencia virtual automatizada e inclusiva para optimizar la relación de la ciudadanía con la Administración Pública. International Journal of Digital Law, Curitiba, v. 1, n. 1, jan./abr. 2020.

SUPERINTERESSANTE. Ilegal. 2014. Disponível em: https://www.youtube. com/watch?v=6PPUY694Csc. Acesso em: 12.10.2018.

SUPERINTERESSANTE. Ilegal: primeiro filme da SUPER mostra a luta de pacientes pela legalização da maconha medicinal no Brasil. Disponível em: https://super.abril.com.br/blog/superblog/ ilegal-primeiro-filme-da-super-mostra-a-luta-de-pacientes-pela-legalizacao-da-maconha-medicinal-no-brasil/. Acesso em: 12.10.2018.

TÁCITO, Caio. Constituições Brasileiras: 1988. Brasília: Senado Federal - Ministério da Ciência e Tecnologia, Centro de Estudos Estratégicos, 2005.

TAVARES, André Ramos. Curso de Direito Constitucional. São Paulo: Saraiva, 2015.

TRF 1. 16a Vara Federal de Brasília. Ação Civil Pública no 0090670-16.2014.4.01.3400. Autor: Ministério Público Federal. Réus: União e Agência Nacional de Vigilância Sanitária. Ajuizamento 
em: 11.12.2014. Disponível em: https://processual.trf1.jus.br/consultaProcessual/processo. php?proc $=00906701620144013400 \&$ secao=DF\&pg=1 \&enviar=Pesquisar. Acesso em: 13.10.2018. TRUFFI, Renan; CARDOSO, Daiene. Auxílio-moradia custa R\$ 817 mi à União. Disponível em: https://politica.estadao.com.br/noticias/geral,auxilio-moradia-custa-r-817-mi-a-uniao,70002176117. Acesso em: 28.09.2018.

UFJF. Pesquisadores defendem uso medicinal de derivados da maconha. Disponível em: https://www2.uff.br/noticias/2018/02/24/pesquisadores-defendem-uso-medicinal-de-derivados-de-maconha/. Acesso em: 30.09.2018.

UNASUS. Anvisa retira canabidiol, derivado da maconha, de lista de substâncias proscritas. Disponível em: https://www.unasus.gov.br/noticia/anvisa -tira-canabidiol-derivado-da-maconha-da-lista-de-substancias-proibidas. Acesso em: 29.09.2018.

UNODC. Drogas: Marco Legal. Disponível em: http://www.unodc.org/lpo-brazil/pt/drogas/marco-legal.html. Acesso em: 29.09.2018.

VALLE, Vivian Cristina Lima López. Serviço Público, Desenvolvimento Econômico e a Nova Contratualização da Administração Pública: o Desafio na Satisfação dos Direitos Fundamentais. In: BACELLAR FILHO, Romeu Felipe; GABARDO, Emerson; HACHEM, Daniel Wunder (Coord.). Globalização, Direitos Fundamentais e Direito Administrativo: novas perspectivas para o desenvolvimento econômico e socioambiental. Belo Horizonte: Fórum, 2011.

VALLE, Vanice Lírio do. Planejamento orçamentário e políticas públicas: explorando uma alternativa de reconciliação pela indução. Revista de Investigações Constitucionais, Curitiba, v. 5, n. 2, p. 113-134, mai./ago. 2018.

VIEIRA, João. 0 homem e as drogas: o penoso caminho do retrocesso. São Paulo: Letras \& Letras, 1996. 